UNIVERSIDADE DE SÃO PAULO

FACULDADE DE ECONOMIA, ADMINISTRAÇÃO E CONTABILIDADE DEPARTAMENTO DE ECONOMIA PROGRAMA DE PÓS-GRADUAÇÃO EM ECONOMIA

CRIMES NOS MUNICÍPIOS PAULISTAS: UM ESTUDO ACERCA DOS CONDICIONANTES SÓCIO-ECONÔMICOS E DEMOGRÁFICOS QUE CONTRIBUEM PARA MAIOR CRIMINALIDADE E QUAIS OS EFEITOS DAS DIFERENTES POLÍTICAS MUNICIPAIS DE SEGURANÇA PARA O COMBATE À CRIMINALIDADE

Estevão Augusto Oller Scripilliti Orientador: Prof. Dr. Denisard Cneio de Oliveira Alves 
Prof. a Dr. ${ }^{\text {a }}$ Suely Vilela

Reitora da Universidade de São Paulo

Prof. a Dr. Carlos Roberto Azzoni

Diretor da Faculdade de Economia, Administração e Contabilidade

Prof. Dr. Joaquim Jose Martins Guilhoto

Chefe do Departamento de Economia

Prof. Dr. Dante Mendes Aldrighi

Coordenador de Programa de Pós-Graduação em Economia 


\section{CRIMES NOS MUNICÍPIOS PAULISTAS: UM ESTUDO ACERCA DOS CONDICIONANTES SÓCIO-ECONÔMICOS E DEMOGRÁFICOS QUE CONTRIBUEM PARA MAIOR CRIMINALIDADE E QUAIS OS EFEITOS DAS DIFERENTES POLÍTICAS MUNICIPAIS DE SEGURANÇA PARA O COMBATE À CRIMINALIDADE}

Dissertação apresentada ao Departamento de Economia da Faculdade de Economia, Administração e Contabilidade da Universidade de São Paulo como requisito para a obtenção do título de Mestre em Economia. 



\section{SÃO PAULO}

2006

\section{FICHA CATALOGRÁFICA}

\section{Elaborada pela Seção de Processamento Técnico do SBD/FEA/USP}

\section{Scripilliti, Estevão Augusto Oller}

Crimes nos municípios paulistas : um estudo acerca dos condicionantes sócio-econômicos e demográficos que contribuem para maior criminalidade e quais os efeitos das diferentes políticas municipais de segurança para o combate à criminalidade / Estevão Augusto Oller Scripilliti. -- São Paulo, 2006.

p.75

Dissertação (Mestrado) - Universidade de São Paulo, 2006 Bibliografia

1. Políticas públicas 2. Criminalidade - São Paulo (SP) I. Universidade de São Paulo. Faculdade de Economia, Administração e Contabilidade II. Título.

$$
\text { CDD - } 320.6
$$




\section{AGRADECIMENTOS}

Agredeço, em primeiro lugar, à minha família pelo apoio e compreensão nos momentos mais adversos desta jornada.

Além de meus pais, Marcello Scripilliti e Tânia Oller Scripilliti, minha irmã Renata e à Rosália, agradeço também à minha namorada, noiva e futura esposa, Teresa Guarita, por toda a paciência e abdicação de tempo para viabilizar este meu projeto pessoal.

Agradeço aos professores da FEA-USP, em especial a meu orientador Denisard Alves e à coordenadora do curso Basília Aguirre, além dos dois membros de minha banca de qualificação, Márcio Nakane e Naércio Menezes, cada qual com sua importância para meu desenvolvimento ao longo do curso e para o amadurecimento deste trabalho final.

Agradeço também àqueles que me incentivaram a buscar esta empreitada e me serviram de exemplo no passado, Octávio de Barros, Zeina Latif e Fábio Akira. Agradeço à FIPE, por todo o apoio financeiro dado ao longo do período de dedicação exclusiva ao curso e ao importante apoio dado pela Sobeet em um momento decisivo de minha vida.

Por fim, agradeço a todos os colegas do mestrado e do doutorado que no período de intensos estudos me ajudaram e tornaram a tarefa árdua muitas vezes prazerosa. Em especial agradeço ao Ricardo Vieira (Cadão), amigo para todas as fases e com quem compartilhei boa parte dos momentos bons e ruins do curso. Ao Fernando Barbosa e ao Luis Henrique Guerra fica também meu agradecimento. 


\section{RESUMO}

A criminalidade é fonte geradora de externalidades negativas para economia e geradora de perda de bem estar social sob vários aspectos. Estudos no Brasil tem abordado com maior freqüência os custos diretos da criminalidade em termos de perdas patrimoniais e de capital humano com crimes.

Este trabalho traz uma contribuição adicional com a análise da efetividade de quatro políticas públicas distintas implementadas em municípios paulistas a partir da segunda metade da década de noventa. Além da melhora de aspectos sócio-econômicos, os municípios paulistas perceberam que podem implementar políticas de segurança complementares ao trabalho estadual e federal para contenção da violência. Disque Denúnica, Lei Seca, Guardas Municipais e Secretaria de Segurança Pública Municipal são exemplos de políticas de segurança implementadas nos municípios paulistas e que se mostraram, em alguns casos, efetivas para o controle dos diferentes tipos de crimes.

São utilizadas estimações em cross section e em forma de painel com variáveis de intervenção (dummies) para cada política de segurança e são avaliados os efeitos sobre o grupo de municípios tratado vis-á-vis o grupo de municípios de controle para avaliar o efeito de cada uma das políticas e sob quais crimes agem de forma mais efetiva. 


\begin{abstract}
Crime generates negative externalities to economy and low welfare for society. Papers in Brazil treat with high frequency direct criminality costs, focusing in patrimonial losses and human resource losses.

This article tries to contribute with the analysis of four municipal security policy effects. Those polices were implemented in São Paulo's districts on 1990's second half. More than better economic and social conditions the São Paulo's districts show that complementar security policy could help to decrease the criminal occurrences in some cases. Disque Denúncia, Lei Seca, Guarda Municipal and Secretaria de Segurança Municipal are the four policies that were tested in this article.
\end{abstract}

Cross section and panel data methods were estimated to measure the effect of different securities policy to reduce crime in districts that implemented such kind of policy. Such methods are using to measure the effects of each policy to reduce criminality and test each kind of crime is better contained by such policies. 


\section{SUMÁRIO}

LISTA DE TABELAS E FIGURAS ............................................. 2

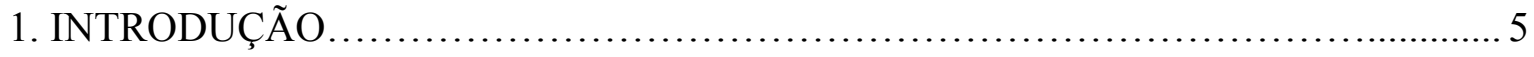

1.1 EVIDÊNCIAS EMPÍRICAS................................................................

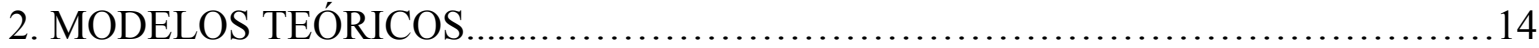

3. DISCUSSÃO DOS DADOS UTILIZADOS NAS ESTIMAÇÕES

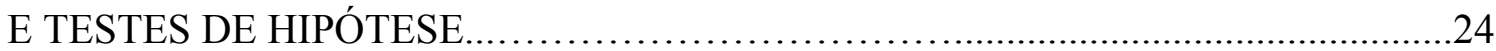

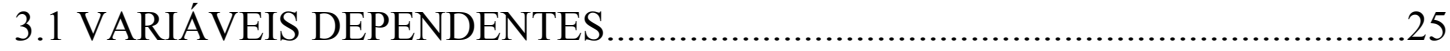

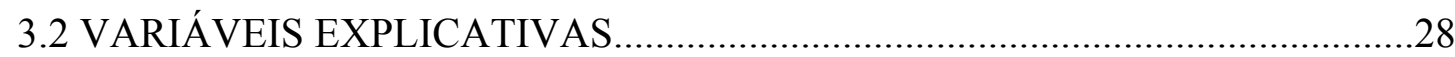

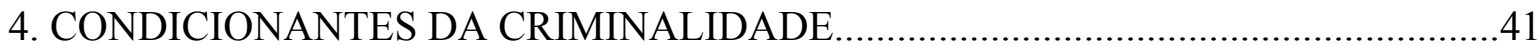

\subsection{CARACTERÍSTICAS DA VIOLÊNCIAS COM}

BASE NOS VETORES PROPOSTOS..........................................................

5. EFEITOS DAS INTERVENÇÕES DE SEGURANÇA PÚBLICA...............................50

6. CONCLUSÃO

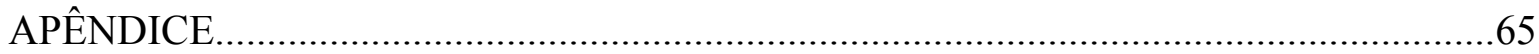

REFERÊNCIAS BIBLIOGRÁFICAS............................................ 71 


\section{LISTA DE TABELAS E FIGURAS}

Figura 1: Condição de equilíbrio do Modelo de Becker (1968)..........................................21

Figura 2: Crimes Totais e Crimes Patrimoniais (por 100 mil habitantes)..............................25

Figura 3: Participação de cada setor na atividade produtiva estadual....................................30

Figura 4: Emprego por setor de atividade................................................................. 31

Tabela 1: Índice Paulista de Responsabilidade Social.....................................................33

Figura 5: Taxa de Urbanização e Densidade demográfica média...........................................35

Tabela 2: Levantamento de mensuração das variáveis......................................................39

Tabela 3: Condicionantes sócio-econômicos e demográficos do crime - Efeito Aleatório......43

Tabela 4: Condicionantes sócio-econômicos e demográficos do crime - Efeito Fixo..............45

Tabela 5: Condicionantes sócio-econômicos e demográficos do crime - Efeito Fixo

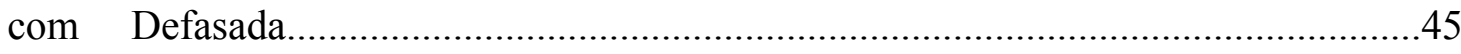

Tabela 6: Condicionantes sócio-econômicos e demográficos do crime - resumo....................46

Tabela 7: Condicionantes sócio-econômicos e demográficos do crime - cross section $2000 . .47$

Tabela 8: Estimadores Diferença-em-diferença de Disque Denúncia....................................54

Tabela 9: Estimadores Diferença-em-diferença de Guarda Municipal..................................56

Tabela 10: Estimadores Diferença-em-diferença de Lei Seca...............................................57

Tabela 11: Estimadores Diferença-em-diferença de Secretaria de Segurança Municipal.........58

Tabela 12: Cross-section para ano 2000 de Crime contra Patrimônio....................................60

Tabela 13: Cross-section para ano 2000 de Homicídio Doloso.............................................60

Tabela 14: Disque Denúncia: Diferença-em-diferença com controle (Crime Patrimonial)......67

Tabela 15: Disque Denúncia: Diferença-em-diferença sem controle (Crime Patrimonial)......67 
Tabela 16: Disque Denúncia: Diferença-em-diferença com controle (Homicídios dolosos)...67

Tabela 17: Disque Denúncia: Diferença-em-diferença sem controle (Homicídios dolosos)...67

Tabela 18: Guarda Municipal: Diferença-em-diferença com controle (Crime Patrimonial)...67

Tabela 19: Guarda Municipal: Diferença-em-diferença sem controle (Crime Patrimonial)...667

Tabela 20: Guarda Municipal: Diferença-em-diferença com controle (Homicídios dolosos)..67

Tabela 21: Guarda Municipal: Diferença-em-diferença sem controle (Homicídios dolosos)...67

Tabela 22: Lei Seca: Diferença-em-diferença com controle (Crime Patrimonial).....................68

Tabela 23: Lei Seca: Diferença-em-diferença sem controle (Crime Patrimonial)......................68

Tabela 24: Lei Seca: Diferença-em-diferença com controle (Homicídios dolosos)..................68

Tabela 25: Lei Seca: Diferença-em-diferença sem controle (Homicídios dolosos)...................68

Tabela 26: SSP: Diferença-em-diferença com controle (Crime Patrimonial).............................68

Tabela 27: SSP: Diferença-em-diferença sem controle (Crime Patrimonial).............................68

Tabela 28: SSP: Diferença-em-diferença com controle (Homicídios dolosos)..........................68

Tabela 29: SSP: Diferença-em-diferença sem controle (Homicídios dolosos)...........................68

Tabela 30:Disque Denúncia: Diferença-em-diferença com controle (log Crime Patrimonial).69

Tabela 31:Disque Denúncia:Diferença-em-diferença sem controle (log Crime Patrimonial)...69

Tabela 32:Disque Denúncia:Diferença-em-diferença com controle (log Homicídios dolosos).69

Tabela 33:Disque Denúncia:Diferença-em-diferença sem controle (log Homicídios dolosos).69

Tabela 34:Guarda Municipal:Diferença-em-diferença com controle (log Crime Patrimonial)..69

Tabela 35:Guarda Municipal:Diferença-em-diferença sem controle (log Crime Patrimonial)...69

Tabela 36:Guarda Municipal:Diferença-em-diferença com controle (log Homicídios dolosos).69

Tabela 37:Guarda Municipal:Diferença-em-diferença sem controle (log Homicídios dolosos).69

Tabela 38: Lei Seca: Diferença-em-diferença com controle (log Crime Patrimonial).................70 
Tabela 39: Lei Seca: Diferença-em-diferença sem controle (log Crime Patrimonial)...............70

Tabela 40: Lei Seca: Diferença-em-diferença com controle (log Homicídios dolosos).............70

Tabela 41: Lei Seca: Diferença-em-diferença sem controle (log Homicídios dolosos).............70

Tabela 42: SSP: Diferença-em-diferença com controle (log Crime Patrimonial)......................70

Tabela 43: SSP: Diferença-em-diferença sem controle (log Crime Patrimonial)......................70

Tabela 44: SSP: Diferença-em-diferença com controle (log Homicídios dolosos)....................70

Tabela 45: SSP: Diferença-em-diferença sem controle (log Homicídios dolosos)....................70 


\section{Introdução}

Este trabalho tem como objeto central de análise diagnosticar qual o processo que leva o indivíduo a decidir pela atividade criminosa. Na verdade a análise se faz em nível agregado e busca entender quais as características que levam alguns municípios a terem maior taxa de criminalidade do que outros e quais as políticas públicas recentes que foram capazes de reduzir a criminalidade nos municípios paulistas.

O estudo do tema da criminalidade é economicamente relevante por ser a criminalidade geradora de externalidades negativas para a sociedade e por esta também criar potenciais alocações subótimas de recursos públicos em outras áreas.

Um ambiente de maior criminalidade é gerador de desutilidade para as pessoas que convivem neste meio, o que resulta em alterações nos preços relativos de determinados bens desta economia. Ou seja, os preços relativos no estado "sem crime" são diferentes dos preços relativos no estado "com crime". Isto fica evidente para setores diretamente ligados ao sentimento de insegurança, como travas para automóveis, ou seguros de automóveis e residenciais, por exemplo.

Com isto, torna-se essencial a compreensão dos fatores que concorrem para taxas de criminalidade elevadas e seus efeitos perversos em termos de bem estar social e de alocações ineficientes de recursos públicos. As alocações ineficientes de recursos derivam de demandas crescentes da sociedade por segurança, seja ela pública ou privada. Gastos com segurança envolvem problema de "agente e principal"1, no caso do setor público, e estão sujeitos também à seleção adversa ${ }^{2}$ nos casos de gastos privados com seguros, por exemplo, e tem como resultado uma alocação ineficiente de recursos na economia como um todo.

\footnotetext{
${ }^{1}$ O problema do "agente e principal" desenvolvido, entre outros, em Hart (1995), consiste em objetivos distintos entre os "agentes" (população que paga impostos e requer segurança) e o "principal" (polícia que provê segurança pública). Como não se tem mecanismos perfeitos de controle da ação do "principal", há a possibilidade de grande dissonância entre a demanda do "agente" e o comportamento do "principal", o que se caracteriza em qualquer contrato e se potencializa no caso das atribuições do setor público (segurança pública em particular).

${ }^{2}$ O problema de seleção adversa, conforme discutido, entre outros, em Williansom e Winter (1993), decorre da assimetria de informação. Neste caso a assimetria se dá entre o contratante de seguro e a seguradora e faz com
} 
Em estudo de Ayres e Levitt (1998) há o diagnóstico no sentido inverso (contra exemplo) de como políticas de segurança por precaução levam a externalidades positivas para a sociedade. Uma medida de segurança que faça a taxa de recuperação de automóveis roubados ser maior e não possibilite a diferenciação entre automóveis que têm e que não têm este dispositivo leva á redução importante do número de furtos de automóveis. Isto beneficia tanto os compradores deste sistema como os não compradores, além do benefício secundário de queda futura no preço dos seguros, representando uma externalidade positiva da precaução não observável das vítimas (nome do próprio artigo) $)^{3}$.

Vale chamar a atenção para o fato de esta política ter característica similar ao Disque Denúncia, por exemplo, que é um dos objetos de análise de efetividade de políticas de segurança abordados no trabalho.

É então sob esta perspectiva que o trabalho procura identificar os principais fatores que levam à alteração na taxa de criminalidade de uma região (município). O diagnóstico é separado em duas etapas: na primeira são testados fatores não relacionados diretamente à política de segurança e que explicam maiores taxas de criminalidade e na segunda etapa é testada a efetividade de diferentes políticas públicas de segurança para contenção da criminalidade.

Além das perdas relacionadas aos vazamentos de renda derivados dos gastos com segurança, há também perdas sociais importantes como as perdas de capital humano que derivam de homicídios, por exemplo. Neste sentido, cabe analisar em separado as características que levam municípios a terem maiores taxas de crime contra o patrimônio e maiores taxas de homicídios. Esta mesma separação é feita na análise da eficácia de políticas de segurança pública (repressivas e/ou preventiva) para reduzir homicídios e crimes contra o patrimônio.

Para o tratamento teórico das condicionantes da criminalidade são utilizados como referência para os testes empíricos sucessivos, os trabalhos apresentados por Becker (1968) e Ehrlich

que na ausência de diferenciação ideal de clientes as seguradoras cobrem prêmios acima dos justos (unffair) para "bons pagadores" para cobertura de "maus pagadores".

${ }^{3}$ Em Measuring Positive Externalities from Unebservable Victim Precaution: An Empirical Analysis of Lojack os autores mostram os efeitos de trava de segurança não observável para redução de roubos de automóveis em determinadas regiões dos EUA que tiverem uma adesão grande deste instrumento. 
(1973). Estes trabalhos tratam a atividade criminosa sob sua dimensão econômica e entendem a opção pelo crime como a ação de um agente racional que decide sob condições de incerteza como alocar seu tempo entre dois tipos de atividade, a saber, atividades lícitas e atividades criminosas.

O crime é visto como uma ação de um agente maximizador que pondera os retornos esperados de duas ações distintas e os riscos embutidos em cada uma destas ações. A partir da ponderação destes parâmetros cada agente aloca seu tempo entre as duas atividades de forma a ter o maior retorno esperado possível de suas ações. Neste sentido o agente é visto, tal qual o apresentado na teoria do consumidor neoclássica, como um agente racional e maximizador de utilidade. Por simplificação, a função utilidade é construída apenas em sua dimensão renda e um vetor de variáveis de estado ${ }^{4}$. Este arcabouço teórico é mais coerente com a explicação de crimes contra o patrimônio, havendo, para o caso de homicídios, a incorporação de aspectos mais abstratos, como questões passionais que influenciam na decisão de cometer homicídio.

Por fim, este trabalho tenta analisar a efetividade de quatro diferentes políticas de segurança e está estruturado em seis capítulos, como se segue:

\section{1 - Introdução}

2 - Modelos Teóricos: são apresentados os dois modelos teóricos simplificados com a abordagem da escolha pelo crime a partir de um cálculo racional do agente e a análise de como políticas que alterem parâmetros em relação à probabilidade de detenção do criminoso e/ou aumentem a punição por crimes se refletem em equilíbrio com menor nível de criminalidade. $\mathrm{E}$ como alterações de condições econômicas e demográficas que alterem os retornos esperados das atividades lícitas e ilegais também implicam em alteração da criminalidade de equilíbrio de determinado município.

\footnotetext{
${ }^{4}$ Vale ressaltar que a função utilidade do indivíduo representativo de cada um dos municípios terá não apenas aspectos econômicos (como renda e emprego), mas também será condicional ao ambiente e às características dos municípios (mais urbanizado, com maior densidade populacional), além do acesso a benefícios advindos de gastos públicos (capturadas em gastos com habitação, transportes, entre outros).
} 
3 - Estatísticas descritivas: são apresentadas estatísticas descritivas das variáveis que são utilizadas nos testes empíricos dos capítulos seguintes. Cabe uma ressalva de que, apesar de se estar trabalhando sob um arcabouço teórico de decisão individual pela atividade criminosa, toda a análise empírica se faz com dados agregados provenientes dos municípios do Estado de São Paulo.

O principal fator que justifica a utilização dos crimes contra o patrimônio e de homicídios como variáveis a serem explicadas está no fato destes tipos de crimes terem uma maior incidência de registros "oficiais" (menos sujeitas a não registro). Isto se deve ao fato de boa parte dos crimes patrimoniais estar sujeita a ressarcimento de seguradoras, por exemplo, e pelos homicídios serem, em sua maior parte, registrados nos IMLs (Instituto Médico Legal) municipais. Com isto, minimiza-se o problema, já tradicional na literatura de criminalidade, de erro de medida da variável dependente. ${ }^{5}$

4 - Condicionantes da criminalidade: os dados são submetidos aos primeiros testes econométricos para compreender quais os condicionantes econômicos e sócio-demográficos que explicam porque alguns municípios são mais violentos do que outros. As estimações são feitas sob a forma de cross section e em painel desbalanceado de dados, com a dimensão temporal com dados anuais para o período 1997 - 2003 e a dimensão de indivíduo representada por todos os municípios do Estado de São Paulo.

A amostra inicial conta com 645 municípios e sete anos (1997-2003). O método de análise dos dados em painel varia entre estimações por efeito aleatório e efeito fixo, a depender das hipóteses que são assumidas sobre a relação entre os termos não observáveis e as variáveis explicativas. As estimações de painel (efeito fixo e efeito aleatório) são feitas de forma desbalanceada por haver variáveis explicativas que não têm observações para um ou mais períodos (tempo).

\footnotetext{
${ }^{5}$ O problema de erro de medida na variável dependente está no fato de o erro vinculado a não contabilização efetiva de todos os crimes poder ser correlacionado com alguma variável explicativa. Neste caso os estimadores por MQO são viesados. No caso em que o erro de medida é não correlacionado com o termo aleatório da regressão hipotética, se a variável dependente fosse diretamente observável, o estimador por MQO gera uma variância do erro sobredimensionada e maior variância nos próprios estimadores.
} 
São discutidos os métodos de estimação e comparados os resultados empíricos sob as diferentes formas funcionais e especificações. Os diferentes resultados são comparados com intuito de se chegar à estimação mais recomendada segundo testes econométricos difundidos ${ }^{6}$. A análise comparativa dos modelos nos dá também uma sinalização da robustez dos resultados encontrados sob diferentes especificações.

5 - Efeito das intervenções de segurança pública: são testadas através da inserção de variáveis de intervenção (dummies) para cada uma das políticas de segurança (discriminando entre o grupo tratado e o grupo de controle) como estas intervenções se refletem em queda da criminalidade nos municípios que as executaram. Para tanto, são feitas estimações que buscam o efeito específico de cada uma das políticas através dos estimadores de diferença-em-diferença para as diferentes políticas sob duas formulações (sem e com outras variáveis de controle).

6 - Conclusões: a partir do conjunto de resultados dos exercícios empíricos são apresentas as conclusões do trabalho e são colocadas possíveis extensões desta linha de pesquisa e de temas similares que podem receber o mesmo tratamento analítico. As conclusões se dão em termos de condicionantes e de políticas públicas que se mostraram mais eficazes para tornar um município menos propenso a altas taxas de criminalidade.

\footnotetext{
${ }^{6} \mathrm{O}$ teste de Hausman, por exemplo, é utilizado para definição de qual a estimação mais apropriada entre efeito fixo e efeito aleatório sob a perspectiva da consistência do estimador.
} 


\subsection{Evidências Empíricas}

A avaliação de políticas de segurança eficazes para controle de criminalidade e redução das perdas sociais que derivam de um ambiente social violento tem sido objeto de intensos estudos, principalmente no âmbito internacional. No Brasil a maior parte dos trabalhos é feita por esforços de sociólogos e de estudiosos criminalistas, sendo o envolvimento de economistas ainda incipiente neste debate. Há grande restrição de dados disponíveis, o que dificulta a ampliação dos estudos na área, mas esforços como da Secretaria de Segurança de São Paulo, com os Estudos Criminológicos anuais, e do Centro de Estudos em Criminalidade e Segurança Pública da UFMG são essenciais para o desenvolvimento do tema no país.

Alguns trabalhos recentes trazem algumas evidências sobre a criminalidade no Brasil. Em Kume (2004), com a utilização de estimativas de painel dinâmico por GMM (Método Geral dos Momentos), que minimiza o problema inerente aos estudos de criminalidade de endogeneidade, o autor chegou a resultados que mostram que a desigualdade de renda e a criminalidade passada se refletem em maior criminalidade presente, enquanto PIB per capita, grau de escolaridade, taxa de urbanização e o PIB afetam negativamente a criminalidade.

Em outro trabalho de Gutierrez, Mendonça, Saschida e Loureiro (2004), com dados para os estados brasileiros, confirmam-se alguns resultados de Kume (2004), contrariam-se outros e são apresentadas novas variáveis relevantes. Assim, a desigualdade é confirmada como fator relevante para explicar a criminalidade. Urbanização, ao contrário do encontrado por Kume (2004), tem efeito positivo para criminalidade. Alguns resultados adicionais, como efeito de maiores gastos estaduais com segurança para queda da criminalidade e inexistência de relação entre pobreza e crime são trazidos neste trabalho.

Em Gomes e Paz (2004) a abordagem se concentra nas características das vítimas criminais no estado de São Paulo e na probabilidade condicional de indivíduos com determinadas características serem vitimizados. Os resultados mostram, a partir da Pesquisa de Condição de Vida do Seade de 1998, que a probabilidade de vitimização é crescente na renda, é maior para homens do que para mulheres, e cresce com anos de estudo e para indivíduos solteiros ou 
divorciados. Para o caso específico de assaltos, descendentes de asiáticos e estrangeiros são mais suscetíveis a este tipo de crime, enquanto ser negro e ser casado são características que tornam menos provável a vitimização. ${ }^{7}$

A dificuldade técnica central abordada pela literatura nos trabalhos sobre criminalidade está no fato de haver um grau de endogeneidade entre nível de criminalidade e políticas de segurança que faz com que os resultados em alguns casos sejam de difícil interpretação. Resultados de trabalhos internacionais chegam muitas vezes em conclusões contraditórias, por exemplo, sobre o efeito de políticas repressivas, mas apresentaremos alguns trabalhos recentes que buscam minimizar este problema da endogeneidade e seus efeitos sobre os resultados das estimações.

Cameron (1988), por exemplo, fez um trabalho (breafing) que apontou que em 18 de 22 estudos sobre criminalidade encontrou-se efeito positivo entre número de policiais e criminalidade.

O grande desafio da literatura de criminalidade, segundo Di Tella (2004), está em: "quebrar esta endogeneidade de forma a permitir a identificação dos efeitos causais da polícia sobre a criminalidade".

Marvel e Moddy (1996) fizeram uma análise em série de tempo que apontou dupla causalidade de Granger entre criminalidade e policiamento, confirmando esta dificuldade técnica de se quebrar a endogeneidade. A estratégia deste trabalho é não se apegar ao número de policiais para cada município, que é um atributo de determinação estadual, mas sim avaliar como intervenções municipais complementares (exógenas) afetaram os níveis de criminalidade dos municípios que as empreenderam nos anos subseqüentes. Assim, espera-se ver minimizado o problema da endogeneidade que cerca os trabalhos deste tema.

Di Tella (2004) utilizou, como forma de tratar o problema da endogeneidade, os atentados terroristas ocorridos em Buenos Aires contra instituições judaicas. Este evento foi tratado como fator exógeno que alterou a distribuição de policiamento para verificar se houve queda de crimes

\footnotetext{
${ }^{7}$ Os resultados dos trabalhos apresentados para o Brasil foram publicados e discutidos em encontro da Anpec do ano de 2004, mas podem ter sido concebidos em anos anteriores.
} 
nas regiões mais policiadas pós-ataques. Os resultados apresentados mostram que houve de fato uma efetividade do policiamento para redução de criminalidade nas adjacências das regiões mais policiadas pós-ataque, mas por outro lado há um aumento dos crimes para regiões um pouco mais distantes, mas ainda na vizinhança destas regiões. Houve evidências de migração do crime, além de sinais de que a efetividade das políticas repressivas é mais sentida no curto prazo, com os criminosos se adaptando ao longo do tempo às novas condições que restringem sua atuação.

Outro estudo que tenta entender os condicionantes que influenciaram para queda da criminalidade nos EUA foi desenvolvido por Levitt (2004). Em Levitt (2004) foram identificados como condicionantes que explicam a redução da criminalidade nos EUA nos anos noventa políticas diretas de segurança, tais como: aumento do número de policiais, crescimento da população carcerária e contenção do avanço do consumo de crack, além de uma política indireta que teria levado á queda da criminalidade, a saber, a liberação do aborto pela Suprema Corte Americana em $1973^{8}$.

O trabalho de Lochner e Moretti (2002) traz evidências de que investimento em educação é um tratamento de longo prazo que reduz criminalidade. Para indivíduos presos e submetidos às políticas de reeducação (grupo dos tratados), a taxa de reincidência futura cai de forma importante em relação ao grupo de controle.

Levitt (2004), em outro trabalho, traz outra forma de minimizar problema da endogeneidade e trata os ciclos eleitorais como eventos exógenos que geram aumento do policiamento e de gastos com segurança e mensura os efeitos destes gastos para redução da criminalidade. A hipótese central é de que governantes, independente da necessidade maior ou menor de segurança, ficam mais propensos a aumentar policiamento e gerar situação de mais conforto à população para serem reeleitos. Isto representa um evento exógeno entre criminalidade e policiamento e permite aferir a causalidade deste aumento de gastos para a criminalidade. O resultado que se chega é

\footnotetext{
${ }^{8}$ Redução de crime por aprovação de aborto estaria relacionada ao fato de filhos indesejados (que são aqueles que foram objeto de aborto) terem maior propensão e se tornarem criminosos. Os filhos indesejados teriam provavelmente um menor esforço de seus pais para dar uma criação razoável e fazer investimento neles e se tornariam, na média, mais propensos a se tornarem criminosos no futuro.
} 
que de fato há redução dos índices de criminalidade em períodos prévios às eleições nos Estados Unidos.

Todos os resultados apresentados são apenas um subgrupo dos extensos trabalhos realizados majoritariamente no exterior. Este trabalho, inspirado em toda esta vasta literatura, é desenvolvido para tentar entender quais políticas públicas foram capazes efetivamente de reduzir crimes nos municípios paulistas e que tipos de crime reduziram (patrimoniais ou homicídios). 


\section{Modelos Teóricos.}

Os modelos teóricos com os quais a literatura internacional trata o tema da criminalidade em sua ótica racional podem ser expressos de forma simplificada pelas abordagens apresentadas por Ehrlich (1973) e pelo trabalho seminal na área, de Becker (1968). As duas abordagens são complementares e são apresentadas de forma resumida com suas principais hipóteses e os resultados de equilíbrio que delas derivam para dar sustentação à parte empírica deste trabalho. A partir das estruturas teóricas destes dois modelos são construídas as hipóteses de racionalidade que validam os resultados dos testes empíricos subseqüentes.

A escolha pela atividade criminosa é vista sempre como uma ação racional de um indivíduo (aqui tratado como agente representativo de cada município) que decide por dispender tempo na atividade criminosa em detrimento de alternativas de ocupação nas atividades lícitas. A escolha da fração de tempo alocada em cada atividade é feita à luz da maximização de utilidade esperada do indivíduo, a partir das considerações acerca das condições do ambiente em que este indivíduo se encontra (condições do município em termos de grau de urbanização e densidade demográfica, por exemplo) e suas expectativas probabilísticas em relação ao futuro (o que caracteriza um ambiente de escolha sob incerteza).

Pode-se representar um modelo de alocação de tempo entre atividades criminosas e lícitas, como feito por Ehrlich (1973), onde o indivíduo aloca seu tempo entre as duas atividades e estas não são mutuamente exclusivas. Com isto o que se tem formalmente é um indivíduo (i) que tem duas opções para alocar seu tempo de trabalho:

$\mathrm{t}_{\mathrm{c}}=$ tempo em atividade criminosa

$\mathrm{t}_{\mathrm{l}}=$ tempo em atividade lícita.

$\mathrm{O}$ restante do tempo o indivíduo aloca em atividades de lazer, que trataremos por $\mathrm{t}_{\text {la. }}$ Uma primeira restrição se refere ao tempo total que o indivíduo pode gastar em suas atividades.

Ou seja, existe a restrição de $\mathrm{T}=$ tempo total disponível, onde: 


$$
\mathrm{T}=\mathrm{t}_{\mathrm{c}}+\mathrm{t}_{\mathrm{l}}+\mathrm{t}_{\mathrm{la}}
$$

Cada indivíduo então aloca seu tempo entre estas três atividades e, para tanto, avalia o retorno esperado de cada unidade de tempo gasta em cada atividade alternativa. Para simplificação, as atividades de lazer não trazem qualquer retorno para o indivíduo. Para as duas outras atividades os retornos são distintos. Na atividade lícita existe certeza com relação ao retorno que se afere pela execução desta atividade (dada pelo salário disponível para determinada atividade). Por outro lado, nas atividades criminosas existe um componente de incerteza que tem de ser levado em conta na escolha do indivíduo. O ambiente de incerteza se caracteriza por ser a atividade ilegal sujeita à retaliação (existe probabilidade de prisão em flagrante, por exemplo). É sob este fator de incerteza que as políticas de segurança (preventivas e/ou repressivas) fazem efeito e alteram o nível de criminalidade de equilíbrio dos municípios na formulação teórica. A representação formal destas hipóteses se coloca da seguinte forma:

Retorno da atividade legal $=\mathrm{W}_{1}$

$\left.\begin{array}{rl}\text { Retorno da atividade criminosa } & =\mathrm{W}_{\mathrm{c}}: \text { com probabilidade }(1-\mathrm{p}) \\ & =\mathrm{W}_{\mathrm{c}}-\mathrm{C}_{\mathrm{c}}: \operatorname{com} \text { probabilidade }(\mathrm{p})\end{array}\right\}$

Com isto, o retorno da alocação de tempo pode ser definido para duas situações.

Situação $a$ - indivíduo que comete crime cumpre pena.

Situação $b$ - indivíduo que comete crime NÃO cumpre pena.

Pode-se então definir o retorno de cada uma das situações como:

$$
\begin{aligned}
& \mathrm{X}_{\mathrm{a}}=\mathrm{W}_{\mathrm{c}}\left(\mathrm{t}_{\mathrm{c}}\right)+\mathrm{W}_{\mathrm{l}}\left(\mathrm{t}_{\mathrm{l}}\right)-\mathrm{C}_{\mathrm{c}}\left(\mathrm{t}_{\mathrm{c}}\right): \quad \text { com probabilidade }(\mathrm{p}) \\
& \mathrm{X}_{\mathrm{b}}=\mathrm{W}_{\mathrm{c}}\left(\mathrm{t}_{\mathrm{c}}\right)+\mathrm{W}_{\mathrm{l}}\left(\mathrm{t}_{\mathrm{l}}\right) \quad \text { : } \quad \text { com probabilidade }(1-\mathrm{p})
\end{aligned}
$$

Disto se segue que o agente maximizará sua utilidade, que será dada por $U_{\mathrm{s}}\left(\mathrm{X}_{\mathrm{s}}, \mathrm{t}_{\mathrm{la}}\right)$ onde $\mathrm{s}=$ estado em que se encontra o indivíduo $(a$ ou $b)$ 
Com isto, pode-se definir como função Utilidade Esperada e a escolha do agente como:

$$
\operatorname{MAX} \quad \operatorname{EU}\left(X_{s}, t_{l a}\right)=(1-p) U\left(X_{b}, t_{l a}\right)+(p) U\left(X_{a}, t_{l a}\right)
$$

O problema se coloca como a opção ótima das variáveis de escolha $\left(t_{c}, t_{1}, t_{l a}\right)$, sujeito às restrições impostas pelas expressões (1), (2) e (3) e pelas condições de: $t_{c}>0, t_{l}>0, t_{1 a}>0$.

Da solução deste problema de maximização, a partir das condições de primeira ordem e pelas condições de Kuhn Tucker ${ }^{9}$, chega-se, conforme representado em Ehrlich (1973), página 526, à condição de equilíbrio do problema, dada por:

$$
-\left(\mathrm{w}_{\mathrm{c}}-\mathrm{w}_{\mathrm{l}}\right) /\left(\mathrm{w}_{\mathrm{c}}-\mathrm{c}_{\mathrm{c}}-\mathrm{w}_{\mathrm{l}}\right)=\mathrm{pU}^{\prime}\left(\mathrm{X}_{\mathrm{a}}\right) /(1-\mathrm{p}) \mathrm{U}^{\prime}\left(\mathrm{X}_{\mathrm{b}}\right)
$$

A condição de equilíbrio que soluciona este simples problema de maximização entre três atividades alternativas e com restrições em desigualdade traz: a) do lado esquerdo - o quociente entre os retornos marginais esperados das atividades sob os dois estados da natureza (com ou sem prisão por ato criminoso; b) do lado direito - o quociente das utilidades marginais esperadas nos dois estados, ponderadas pelas suas probabilidades de ocorrência, dadas por $p$ e (1-p) respectivamente.

Vale ressaltar que $\mathrm{w}_{\mathrm{c}}, \mathrm{w}_{\mathrm{l}}, \mathrm{c}_{\mathrm{c}}$ são variáveis que representam: o retorno marginal da atividade criminosa, que será condicional às características particulares de cada município (riqueza do município, desigualdade de renda, entre outros), o retorno marginal da atividade lícita e o custo marginal da atividade criminosa no estado em que existe captura do criminoso, respectivamente.

Para o escopo de análise que é tratado neste trabalho o modelo acima é generalizado para agentes representativos dos municípios, com os resultados teóricos modelados para os indivíduos transferidos para este novo nível de agregação da análise empírica.

\footnotetext{
9 As condições de Kuhn Tucker foram estabelecidas para garantir a resolução de problemas de maximização/minimização com restrições em desigualdade.
} 
Becker (1968) traz em sua modelagem aspectos de agregação que colaboram para o nível de análise deste trabalho. Becker, em seu modelo, coloca a ação do estado e não a ação do indivíduo como ponto focal da análise. O objeto analítico central deixa de ser o indivíduo maximizador de utilidade esperada (como em Ehrlich) e passa a ser a estrutura de punições (sistema policial, judiciário, sistema carcerário e políticas de segurança preventivas e/ou repressivas) que se traduz em maior/menor probabilidade de detenção percebida pelos criminosos e que resulta na menor perda social possível para esta sociedade.

A abordagem de Becker é focada na decisão do planejador central sobre regras e instrumentos de punição e pode ser apresentada de forma simplificada a partir da construção de uma função de perda social dada por:

$$
\mathrm{D}=\mathrm{H}-\mathrm{G}
$$

Onde,

$\mathrm{D}$ = perda líquida da sociedade com crime

$\mathrm{H}=$ perda dos que sofrem com o crime

$\mathrm{G}=$ retorno dos criminosos.

O nível de atividade criminosa (número de ocorrências criminais de equilíbrio para dadas condições de punições e de regras desta sociedade) é definido por uma função $\mathrm{O}$.

As funções $H$ (perda dos que sofrem com crime) e $G$ (retorno dos criminosos) são crescentes em O (nível de criminalidade). Maior nível de criminalidade leva a maior perda social e simultaneamente a maior ganho dos criminosos, como contraparte. $\mathrm{O}$ efeito marginal líquido para sociedade é, portanto, resultante do efeito marginal de incrementos da criminalidade nas funções perda $(H)$ e retorno $(G)$.

Ou seja, d H/d O $>0 ; \mathrm{d} \mathrm{G}_{\mathrm{i}} / \mathrm{d} \mathrm{O}>0$ 
As derivadas segundas das duas funções em relação a $\mathrm{O}$ divergem:

H' $>0$ (perda marginal tem aceleração crescente conforme nível de criminalidade cresce). $\mathrm{G}^{\prime}$ ' $<0$ (ganho marginal cresce a taxas decrescentes com relação ao nível de criminalidade). Com isto tem-se que $\mathrm{D}^{\prime \prime}(\mathrm{O})>0$.

Ou seja, a perda líquida da sociedade (D) tem taxas crescentes com o aumento do nível da atividade criminosa desta sociedade.

Define-se adicionalmente uma função Custo de Apreensão (C) do criminoso, que terá como argumentos: a capacitação do sistema policial e do sistema judiciário, dados pela função A (eficiência do sistema de punições) ${ }^{10}$. A função A (eficiência do sistema de punições) é definida como:

$A=f(m, j) \quad$ e $\quad C=f(A)$

Onde, $\mathrm{m}=$ eficiência policial, $\mathrm{j}=$ eficiência judiciário.

\section{Redefini-se A:}

$\mathrm{A}=\mathrm{p}^{*} \mathrm{O}$

Onde, $\mathrm{p}=$ probabilidade de criminoso ser pego e $\mathrm{O}$ é a função relacionada ao nível de criminalidade.

Tem-se então que $\mathrm{dC} / \mathrm{dA}>0$. Com a redefinição de $\mathrm{A}$ em (8) isto implica que:
$\mathrm{dC}(\mathrm{pO}) / \mathrm{dp}>0$
$\mathrm{e}$
$\mathrm{dC}(\mathrm{pO}) / \mathrm{dO}>0$

\footnotetext{
${ }^{10}$ Será sob esta função A que as políticas de segurança que afetam eficiência policial (termo $\mathrm{m}$ definido na função A) exercerão seu papel redutor do nível de criminalidade de equilíbrio.
} 
Ou seja, tanto o aumento da probabilidade do criminoso ser capturado, quanto o incremento da taxa de criminalidade em determinada sociedade, implicam incremento no custo total de apreensão de criminoso nesta sociedade, o que é um resultado intuitivo.

Por fim, há a hipótese de que os custos marginais de apreensão dos criminosos crescem a taxas crescentes, C'’ $(\mathrm{pO})>0$, tanto com incremento da probabilidade de prisão (p) quanto com aumento do nível de criminalidade $(\mathrm{O})$.

A decisão de uma pessoa de cometer um ato criminoso está vinculada à utilidade relativa que esta atividade trará em relação às demais atividades que este indivíduo pode potencialmente executar, dado o seu tempo disponível. Neste sentido, a análise se aproxima à apresentada em Ehrlich (1973). A diferença está no fato de as atividades lícita e criminosa, em Becker, serem vistas como mutuamente exclusivas.

O número de crimes que será cometido em determinada sociedade é modelado como:

$\mathrm{O}_{\mathrm{j}}=\mathrm{O}_{\mathrm{j}}\left(\mathrm{p}_{\mathrm{j}}, \mathrm{f}_{\mathrm{j}}, \mathrm{u}_{\mathrm{j}}\right)$,

Onde:

$\mathrm{p}_{\mathrm{j}}=$ probabilidade de criminoso ser condenado

$\mathrm{f}_{\mathrm{j}}=$ punição do crime

$\mathrm{u}_{\mathrm{j}}=$ vetor com demais variáveis de estado que influenciam na decisão do criminoso (renda, educação, urbanização, transporte, habitação, etc).

Aumentos na probabilidade de prisão, ou na pena a ser cumprida pelo ato ilícito, implicam em redução do número de crimes de equilíbrio nesta sociedade, mantidos os demais fatores fixos. É esta formulação teórica e seus resultados de estática comparativa que são testados empiricamente nos próximos capítulos.

Estas hipótese podem ser expressas por:

$$
\left.\begin{array}{l}
\partial \mathrm{O}_{\mathrm{j}} / \partial \mathrm{p}_{\mathrm{j}}<0 \\
\partial \mathrm{O}_{\mathrm{j}} / \partial \mathrm{f}_{\mathrm{j}}<0
\end{array}\right\}
$$


Em Becker (1968), página 179, o autor afirma que para agregação pode-se considerar a função $\mathrm{O}=\mathrm{O}(\mathrm{p}, \mathrm{f}, \mathrm{u})$, onde a ausência de subscritos está relacionada à utilização da média amostral. $\mathrm{O}$ autor afirma que estas funções podem ser consideradas com as mesmas propriedades da função individual $\mathrm{O}_{\mathrm{j}}$, o que nos é de grande valor pelo escopo agregado deste trabalho.

A função de perda social será então minimizada pela escolha das variáveis $p$ (probabilidade de prisão), $f$ (pena pelo crime).

O critério então para escolha do binômio $p, f$ é o de BEM ESTAR.

Define-se para tanto uma função perda de bem estar social $(L)$ que será minimizada pelo agente central. Esta função é definida como:

$$
\mathrm{L}(\mathrm{D}, \mathrm{C}, \mathrm{f}, \mathrm{O})
$$

As variáveis de escolha na minimização de $L$ são $(f, p)$.

L então pode ser reescrito como:

$\mathrm{L}=\mathrm{D}(\mathrm{O})+\mathrm{C}(\mathrm{p}, \mathrm{O})+\mathrm{pfO}$

onde o último termo (pfO) da equação (11) diz respeito ao custo social da punição pelo crime. Com isto, o problema de minimização pode ser escrito como:

$\operatorname{Min}_{f, p} \quad L(D, O, f, C)$

Onde as condições de primeira ordem são dadas por:

$\left.\begin{array}{l}\partial \mathrm{L} / \partial \mathrm{f}=\mathrm{D}^{\prime}\left(\mathrm{O}_{\mathrm{f}}\right)+\mathrm{C}^{\prime}\left(\mathrm{O}_{\mathrm{f}}\right)+\mathrm{pO}+\mathrm{pfO}_{\mathrm{f}}=0 \\ \partial \mathrm{L} / \partial \mathrm{p}=\mathrm{D}^{\prime}\left(\mathrm{O}_{\mathrm{p}}\right)+\mathrm{C}^{\prime}\left(\mathrm{O}_{\mathrm{p}}\right)+\mathrm{pO}+\mathrm{pfO}_{\mathrm{p}}=0\end{array}\right\}$ 
O que, resolvendo, remete à condição de equilíbrio que soluciona o problema, dada pelas equações:

$\mathrm{D}^{\prime}+\mathrm{C}^{\prime}=-\operatorname{pf}\left(1-1 / \dot{\varepsilon}_{\mathrm{f}}\right)$

$\mathrm{D}^{\prime}+\mathrm{C}^{\prime}+\mathrm{C}_{\mathrm{p}}\left(1 / \mathrm{O}_{\mathrm{p}}\right)=-\mathrm{pf}\left(1-1 / \dot{\varepsilon}_{\mathrm{p}}\right)$

Com $\dot{\varepsilon}_{\mathrm{f}}=-(\mathrm{f} / \mathrm{O}) * \mathrm{O}_{\mathrm{f}} \quad ; \quad \dot{\varepsilon}_{\mathrm{p}}=-(\mathrm{p} / \mathrm{O}) * \mathrm{O}_{\mathrm{p}}$

Onde o lado esquerdo das equações (14) e (15) refere-se aos custos marginais do crime (perda social marginal + custo social marginal por apreensão dos presos) em relação às variáveis $(f)$ e (p) respectivamente. $\mathrm{E}$ o lado direito das equações refere-se às receitas marginais em relação às mesmas variáveis $(f)$ e $(p)$, respectivamente, sendo a condição de equilíbrio estabelecida no ponto onde as receitas marginais e os custos marginais em relação às duas variáveis de escolha se igualam.

Graficamente as equações (14) e (15) e a condição de equilíbrio podem ser representadas como segue abaixo na Figura 1.

CMg - Rmg

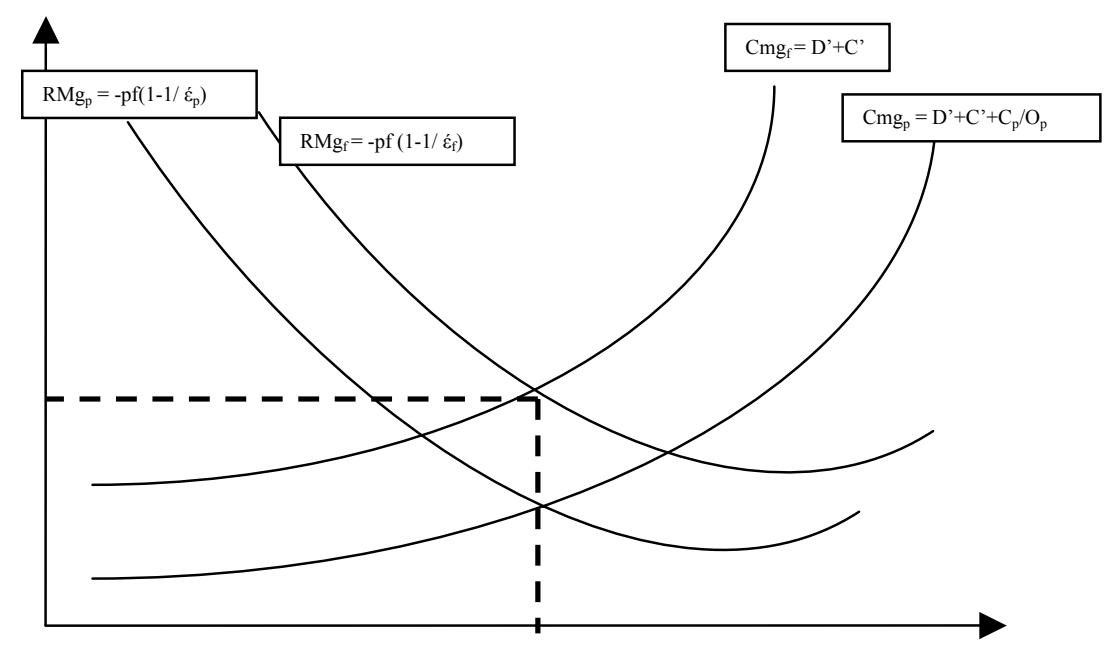

Número de Crimes 
A condição de equilíbrio, portanto, é dada quando os custos marginais e as receitas marginais de incremento na probabilidade de que um criminoso seja pego e de aumento nas punições impostas aos criminosos se igualem. Sempre a análise se refere a perdas e ganhos em termos sociais, definidos pela função L. Políticas públicas que representem alteração nos custos marginais de apreensão, ou em aumento dos custos marginais de manutenção dos criminosos capturados, alterarão o equilíbrio (taxa de criminalidade) deste sistema.

É sob estes dois modelos teóricos formulados, o de escolha individual, que remete a Ehrlich (1973), e o modelo de minimização das perdas sociais apresentado em Becker (1968), que se compreende como as características distintas de municípios levam a diferentes funções D (perdas sociais) e C (custo de apreensão) que implicam em taxas de equilíbrio de criminalidade diferenciadas para os diferentes municípios do Estado de São Paulo. A avaliação de quais as condições sócio-econômicas que levam a maior probabilidade de um indivíduo cometer crimes e quais as políticas públicas que podem reduzir esta probabilidade são as respostas finais a que se pretende chegar nos próximos capítulos.

Sob diferentes condições de renda e de oferta de serviços públicos para os diferentes municípios paulistas é de se esperar condições de equilíbrio com taxas de criminalidade diferenciadas entre os municípios, ou mesmo em um mesmo município ao longo do tempo.

A Secretaria de Segurança Publica de São Paulo, atavés de seus Estudos Criminológicos, avaliou como algumas políticas resultaram em quebras estruturais (menor criminalidade) de séries temporais da criminalidade nos municípios que as implementaram. Estas quebras se dão em virtude da percepção de alteração de alguns parâmetros percebidos pelos criminosos, tais como: maior probabilidade de prisão e sistemas de punição e carcerário menos brandos, por exemplo. Neste mesmo sentido, Corman e Mocan (2000) fizeram, a partir de dados de alta freqüência (mensais) para cidade de Nova Iorque, um estudo que comprova que existe efeito positivo (menor criminalidade) da intensificação de políticas repressivas ao crime na cidade.

Este trabalho pretende complementar este foco de análise com a utilização de métodos estatísticos diferenciados dos utilizados pela SSP (Secretaria de Segurança Pública) e que 
incorporam as análises de cross section, de dados em painel e de estimadores de diferença-emdiferença para executar a avaliação da eficácia das políticas de segurança, além de avaliar como a dinâmica de variáveis de estado também colabora para redução da criminalidade pela alteração dos parâmetros de retorno relativo das atividades legais e ilícitas. 


\section{Discussão dos dados utilizados nas estimações e testes de hipótese.}

Este capítulo apresenta, apenas de forma descritiva, parte das variáveis que são utilizadas nos testes empíricos subseqüentes.

Cabe uma ressalva sobre a dificuldade de harmonização dos dados para formatação de um painel que possa ser estimado de forma balanceada. Esta dificuldade deriva do fato de as variáveis disponíveis terem periodicidade e intervalos de mensuração distintos. Como esforço metodológico adicional, todas as variáveis foram normalizadas pela população de cada município. Assim sendo, os exercícios empíricos sempre tratam as variáveis em escala per capita, ou por 100.000 habitantes, para que as variáveis sejam comparáveis entre municípios de diferentes portes populacionais.

A formatação ideal dos dados para a parte empírica deste trabalho, que seria plenamente coerente com os modelos teóricos expostos no capítulo anterior e que facilitaria o tratamento analítico deste trabalho, seria a consideração das variáveis dependentes (crime contra o patrimônio e homicídios dolosos) que temos disponíveis para todo o período de 1997-2003, regredidas contra variáveis explicativas diretamente observáveis para o mesmo período e que representassem diretamente: o retorno de atividades lícitas, o custo de oportunidade de se ingressar no mercado do crime (retorno da atividade ilícita), gastos públicos com segurança e variáveis de estado adicionais. Entretanto, não há a disponibilidade da totalidade destas variáveis para todos os períodos de tempo, o que requer lançar mão, em alguns casos, de variáveis proxys que substituam estas variáveis “ideais”, mas que não são diretamente observáveis.

A seguir são descritas as variáveis, com algumas de suas estatísticas descritivas, que são utilizadas na análise empírica. 


\subsection{Variáveis Dependentes}

Como variável dependente considerou-se a hipótese de trabalhar com as Ocorrências Policiais Totais, criminais e não criminais contabilizadas pelos diferentes municípios a cada ano. Estas ocorrências são registradas pelos distritos policiais, podendo ser criminais, contravencionais (não chega a caracterizar delito) e não criminais (suicídio, por exemplo) ${ }^{11}$. A defesa de um indicador de criminalidade amplo está no fato de que a percepção de violência, que é a maior fonte geradora de externalidade negativa do crime para o bem estar da sociedade, está relacionada a qualquer tipo de violência, e não estritamente aos crimes que se relacionam com perdas patrimoniais ou homicídios. Entretanto, pelo motivo da não contabilização de boa parte dos crimes optou-se por outras variáveis dependentes.

\section{EVOUÇÃO DOS CRIMES TOTAIS E CRIMES CONTRA O PATRIMÔNIO (POR 100.000 HABITANTES) NO ESTADO DE SÃO PAULO}

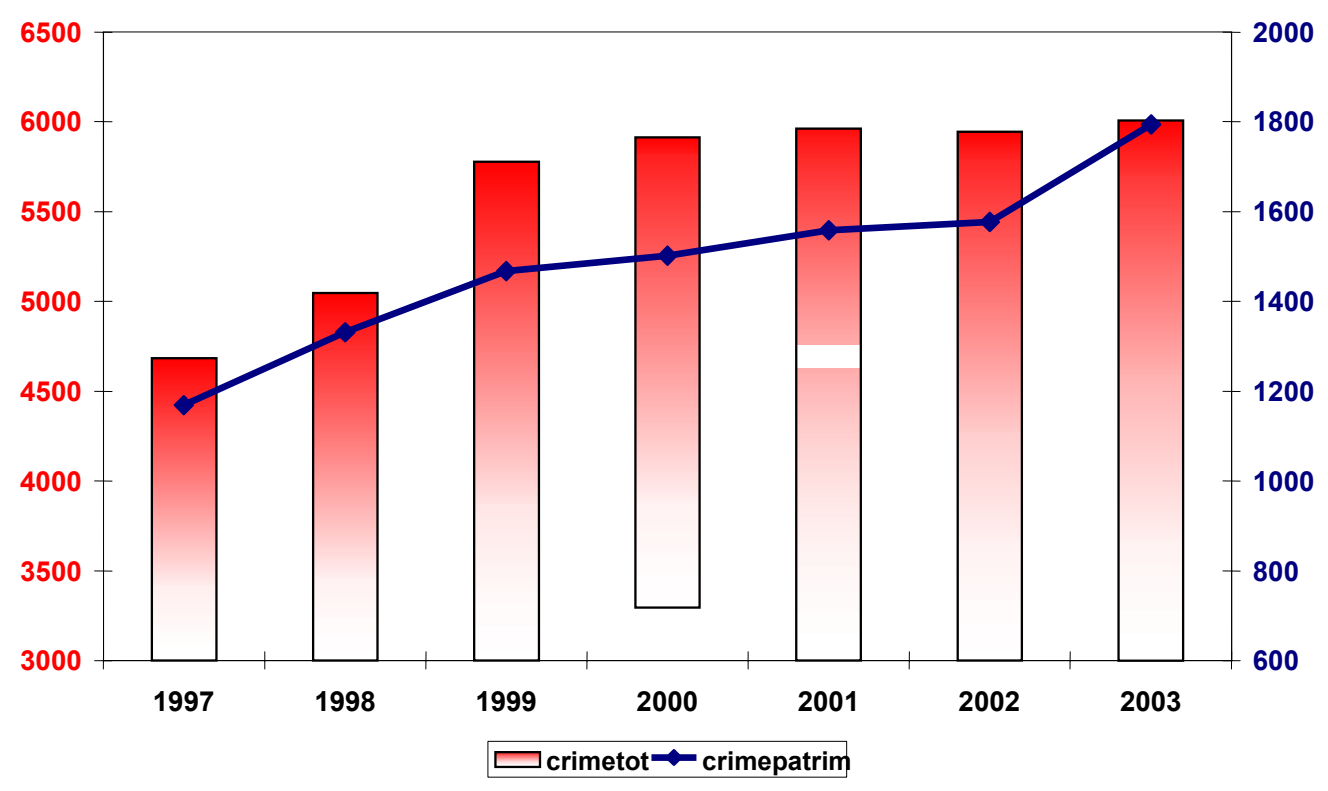

É exatamente sobre este fenômeno de crescente número de ocorrências criminais ao longo da segunda metade dos anos noventa e relativa estabilização desta trajetória no começo desta década que este estudo faz sua análise. O incremento no número de ocorrências ao longo da

\footnotetext{
${ }^{11}$ Fontes primárias de dados de criminalidade: Fundação Seade, Secretaria de Estado da Segurança Pública-SSP/ Delegacia Geral de Polícia-DGP/ Departamento de Administração e Planejamento-DAP/ Núcleo de Análise de Dados
} 
segunda metade da década de noventa, se considerarmos tanto os crimes totais quanto os crimes patrimoniais para os 645 municípios paulistas, evidencia uma situação de deterioração do nível de segurança da população. As perdas sociais neste cenário aumentam, tanto em termos de dispêndios de mais recursos públicos e privados com segurança, quanto por conta da perda de bem estar inerente ao sentimento rotineiro de maior insegurança.

Como alternativa de variável dependente foi utilizado o número de ocorrências policiais de crimes contra o patrimônio, que se define como: “ofensa ao interesse patrimonial, que é, por sua vez, um complexo de relações jurídicas com valor pecuniário", segundo definição da própria Secretaria de Segurança Pública do Estado de São Paulo (fonte primária dos dados de criminalidade).

A utilização desta variável, em detrimento do total de ocorrências criminais, se justifica, entre outros fatores como a minimização do erro de medida da variável dependente, pela manutenção da coerência da parte empírica com os modelos teóricos apresentados. A coerência das estimações para com os modelos teóricos de racionalidade econômica fica mais evidente com a utilização de crime contra o patrimônio como variável dependente.

Complementarmente, para utilização de homicídios dolosos como variável dependente é necessário incorporar uma dimensão adicional ao modelo teórico, pois pode haver um componente passional em parte das ocorrências que não será capturado por nenhuma variável diretamente observável. Estudos mostram que há, por exemplo, grande relação entre incidência de homicídios dolosos e consumo de álcool da população local ${ }^{12}$. Porém, se pensarmos que as características não observáveis que influenciam para maior ocorrência de homicídios, ou são constantes no tempo, ou não estão correlacionadas com as demais variáveis explicativas (componente passional independe, por exemplo, de grau de urbanização, de gastos com transportes, de renda média da população, etc.), isto não implica em viés dos coeficientes estimados.

\footnotetext{
${ }^{12}$ Ver na página trinta e seis deste tranbalho citações de resultados para estudos no Brasil e em outros países que vinculam bebidas alcoólicas com número de homicídios
} 
Um fator adicional favorável à utilização apenas de crimes contra o patrimônio e de homicídios dolosos está no fato destes crimes serem menos sujeitos ao problema de não contabilização. Parte dos patrimônios em ativo físico está segurada, o que faz com que o Boletim de Ocorrência seja feito para o ressarcimento junto às seguradoras. Homicídio doloso também goza desta característica desejável que minimiza o problema de erro de medida da variável dependente, por ser contabilizado no IML (Instituto Médico Legal) local.

Outros crimes tendem a ter uma taxa de não contabilização maior pela ausência de incentivo para ser lavrada queixa crime, seja por conta da baixa probabilidade de se reaver o que foi lesado, seja por medo de retaliação, como nos casos de violência doméstica, por exemplo, o que gera vieses nas estimações. Neste sentido, o problema de erro de medida da variável dependente, que pode estar correlacionada de alguma forma com as variáveis explicativas, fica minimizado sob a utilização de crime contra o patrimônio e homicídios dolosos como variáveis dependentes.

A análise do comportamento das duas variáveis (crimes contra o patrimônio e homicídios dolosos) leva à conclusão de deterioração, na média do período estudado, do cenário de criminalidade no estado de São Paulo. Resta entender, como primeiro objeto de estudo deste trabalho, quais as condições sócio-econômicas e demográficas que permitiram este aumento da violência no Estado de São Paulo e quais as características que fazem de um município mais propenso à ocorrência destes tipos de crime. O segundo objeto de estudo é compreender a efetividade de diferentes políticas de segurança implementadas pelos municípios paulistas para contenção desta trajetória de deterioração ocorrida na segunda metade dos anos noventa. 


\subsection{Variáveis Explicativas}

As variáveis explicativas incorporadas nos diversos modelos econométricos apresentados nos capítulos seguintes estão agrupadas em três vetores.

O primeiro vetor diz respeito às variáveis de caráter econômico e que contemplam: o nível de renda médio de um município e as condições gerais de emprego (desemprego).

O segundo vetor está ligado à situação sócio-demográfica de cada município. Neste vetor estão contidas variáveis como: taxa de urbanização do município, indicadores de desenvolvimento humano (IDH) ligados à educação e à longevidade da população ${ }^{13}$, densidade populacional, população total do município, entre outras variáveis.

O terceiro vetor está ligado aos dispêndios dos municípios em educação, gastos com saúde, gastos com previdência, gastos com transporte, gastos com habitação, gastos em custeio e gastos totais de cada município, sempre normalizadas pelo número de habitantes de cada município.

O primeiro vetor é denominado de "vetor Renda" (R).

Fazem parte de (R): IPRS- Riqueza (Índice Paulista de Responsabilidade Social medido pelo Seade) e nível de emprego geral do município, medido pela RAIS ${ }^{14}$ do Ministério do Trabalho e Emprego.

\footnotetext{
${ }^{13}$ As variáveis que medem condições de desenvolvimento humano geram, a partir de metodologia desenvolvida pela Fundação Seade, números índices que variam de 0 a 100 para as condições médias da população em setores como educação, renda e expectativa de vida. Estas variáveis são medidas pelo IPRS (Índice Paulista de Responsabilidade Social) computadas pela Fundação Seade para todos os municípios do estado, mas sem periodicidade regular. A Fundação Seade tem para tanto apoio da Assembléia Legislativa de São Paulo que garante a verba para execução desta pesquisa

${ }^{14}$ Os dados de emprego formal são apresentados como o "número de empregos ocupados" e se referem ao total de vínculos empregatícios remunerados, efetivamente ocupados por trabalhadores com carteira de trabalho assinada (regime da Consolidação das Leis do Trabalho - CLT), estatutários (funcionários públicos) e trabalhadores avulsos, temporários e outros, desde que formalmente contratados em uma determinada data, informados pelos estabelecimentos quando da elaboração da Relação Anual de Informações Sociais - RAIS, do Ministério do Trabalhoe Emprego.
} 
A inclusão destas variáveis se justifica teoricamente pelo fato de ser a possibilidade de aferir renda no setor legal o preço sombra, ou o custo de oportunidade, de se ingressar em atividades criminosas. $\mathrm{O}$ aumento dos índices de criminalidade pode, em princípio, estar relacionado a piores condições de renda e emprego no setor legal. Condições ruins no setor "legal" implicam menor custo de oportunidade de se optar pela atividade criminosa. O que se tem aqui são bens substitutos, atividade legal - que gera salários - e atividade ilícita - que gera renda através da revenda do patrimônio furtado e tem implicitamente um risco de prisão - conforme já explicitado no modelo teórico de Ehrlich (1973). Além disto, municípios com maior renda estão associados a melhores condições patrimoniais, o que implica um retorno esperado maior também para atividades ilegais. Há também uma tendência de municípios ricos atraírem fluxos populacionais em busca de oportunidades e serem mais propensos a aumento de desigualdade de renda (como são os casos das grandes metrópoles e centros urbanos brasileiros).

As variáveis que medem diretamente nível de renda das famílias de forma mais ampla são mensuradas apenas nos Censos $^{15}$, que ocorrem a cada dez anos, sendo os dois últimos os de 1991 e 2000. Estas informações não resolvem nosso problema, dado o período amostral de nossas variáveis dependentes (1997-2003). Utilizaremos então o IPRS-Riqueza como variável da dimensão renda. Ela será a proxy da renda censitária dos municípios. Conforme definido em Wooldridge (2003), página 295, proxy é: “uma variável observável que é relacionada, mas não idêntica, a outra variável explicativa não observável inclusa na análise de uma regressão múltipla".

Outra variável que integra o vetor renda $(\mathrm{R})$ é o nível geral de emprego no setor formal da economia, também apurada anualmente para os diferentes municípios através da RAIS, elaborada pelo Ministério do Trabalho e Emprego, que considera todos os trabalhadores empregados pela CLT (Código de Leis Trabalhistas), além dos trabalhadores avulsos e temporários, desde que formalmente contratados. Há a observação pelo próprio Ministério do Trabalho e Emprego de que a comparação entre RAIS é delicada e está sujeita a erro por omissões, ou por respostas por parte das empresas não fidedignas dos questionários em que se

\footnotetext{
${ }^{15}$ Censos Demográficos são publicados pelo IBGE (Instituto Brasileiro de Geografia e Estatística) a cada dez anos, o que é insuficiente para nossa base amostral que vai de 1997 até 2003 e contempla apenas o Censo de 2000 neste ínterim.
} 
baseiam as pesquisas. Como consideramos que os incentivos às omissões não devam ter se alterado neste curto espaço de tempo amostral (1997-2003), seu efeito em termos de viés de estimadores fica minimizado.

Cabe apenas uma digressão sobre uma mudança qualitativa importante ocorrida no período de análise nos dados de emprego. Como na parte empírica apenas o emprego total é utilizado como variável explicativa, a alteração qualitativa da composição do emprego ao longo do tempo não será devidamente capturada, mas fica aqui uma análise e o reconhecimento de que este é um fator importante a ser observado. Abaixo está representada a evolução da participação do número de estabelecimentos por atividade econômica no período 1997-2003, que nos dá a dinâmica inter setorial do emprego e suas implicações em termos de capacidade de geração de renda no setor "legal".

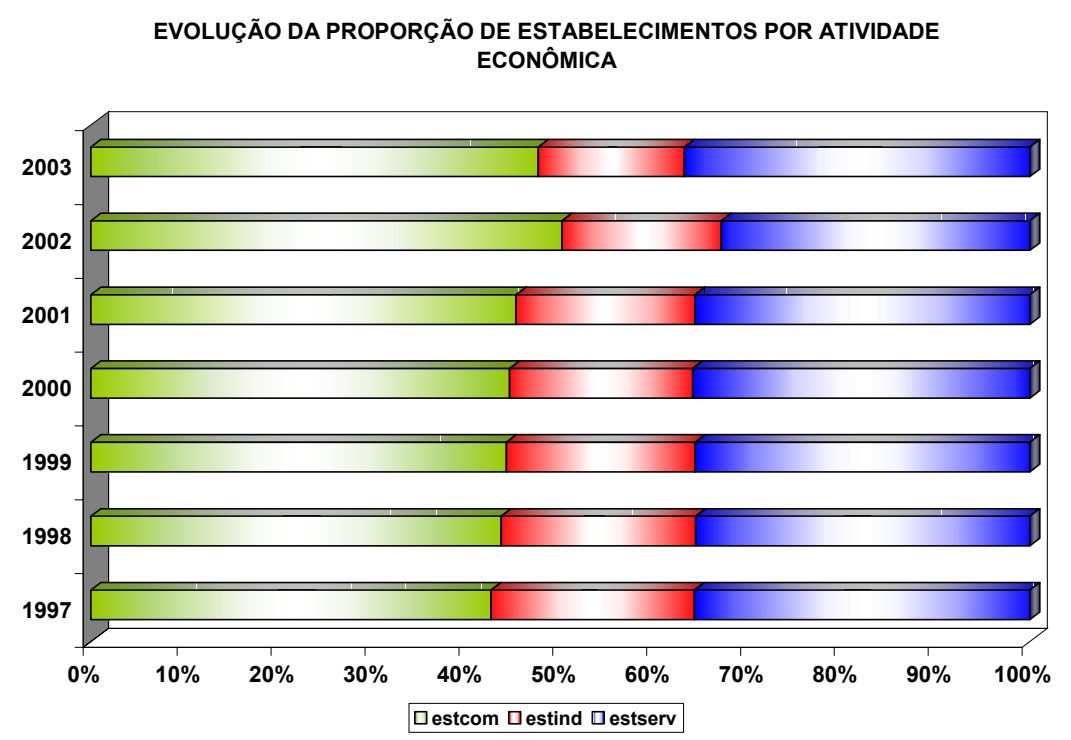

Há a sinalização da ocorrência de um ganho de participação relativa do setor comercial, em detrimento do setor industrial neste período. O setor de serviços, em média, também ganhou participação relativa. Houve rápida perda de peso do setor industrial na economia como um todo. Diversos estudos para economia brasileira mostram que o setor industrial é o setor que tem mais participação de trabalhadores formais em seu quadro de funcionários. O trabalhador formal é, em média, mais produtivo que o trabalhador informal, por haver maior comprometimento da empresa em investir em capital humano (dado o alto custo de demissão e admissão de outro 
funcionário) e por haver maior comprometimento do empregado em apresentar maior produtividade (por ser o salário no setor formal maior que no setor informal). ${ }^{16}$

A deterioração da qualidade do emprego, independente da evolução da quantidade total de empregos, com a migração de parte da mão-de-obra para setores menos formalizados e menos produtivos, gera potencialmente uma redução da produtividade do trabalho e do salário médio da sociedade como um todo.

EVOLUÇÃO DE EMPREGO POR SETOR DE ATIVIDADE

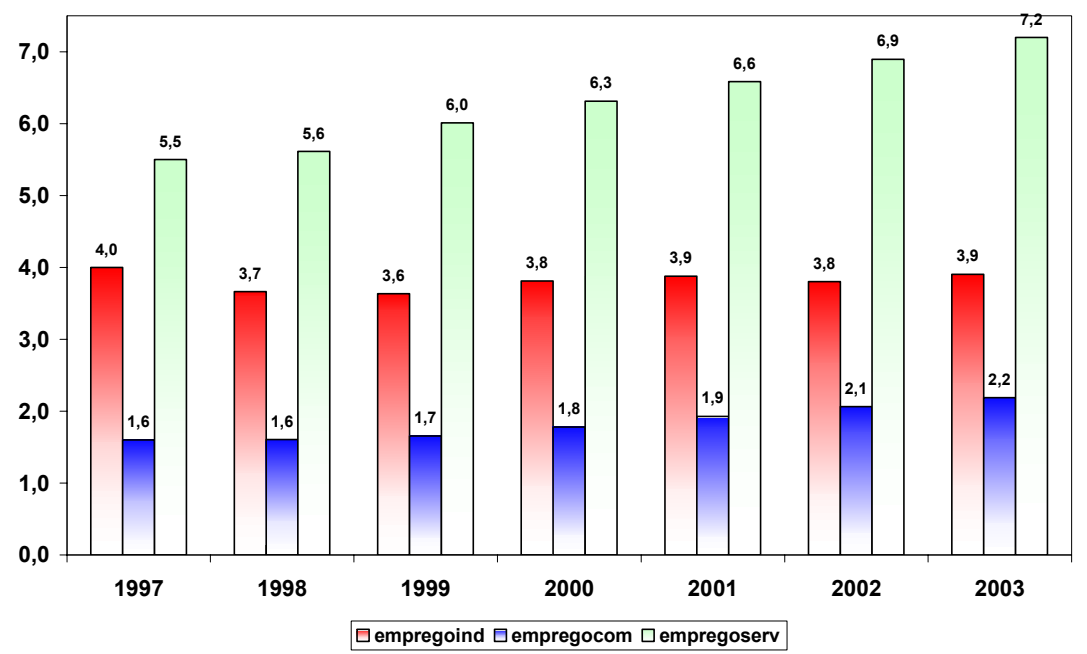

Segundo o modelo teórico apresentado em Ehrlich (1973), uma queda de salário no setor formal, ceteris paribus, torna o custo de oportunidade de se recorrer ao crime menor, o que leva a um aumento do nível de criminalidade de equilíbrio nesta sociedade. Assim, há um movimento de deterioração da qualidade do mercado de trabalho que parece coerente com a deterioração da criminalidade no período analisado.

A importância de analisar a dinâmica do setor industrial deriva do setor industrial, além de ser o setor onde o trabalhador é mais produtivo, segundo diversos estudos, também ser sempre visto como uma boa proxy para o comportamento da economia como um todo, por seus efeitos multiplicadores em termos de emprego e renda para economia. Neste sentido, em muitos trabalhos macroeconômicos é utilizada como proxy para o produto real da economia (PIB) a

\footnotetext{
${ }^{16}$ Em Silva e Kassouf (2000) há uma ampla avaliação sobre diferenciais de produtividade e de remuneração entre os trabalhadores no mercado formal e informal, além de uma discussão acerca do aspecto de discriminação no mercado de trabalho.
} 
produção industrial, por esta ter uma mensuração mensal, vis-à-vis a mensuração trimestral do PIB. Esta utilização sinaliza a pertinência desta ressalva acerca do comportamento particular da indústria como referencial para o comportamento geral da economia brasileira.

A piora do emprego industrial também pressiona os demais setores da economia, com um excesso de oferta de mão-de-obra nos setores comercial e de serviços por conta de migração dos desempregados do setor industrial. Esta migração pode ter efeitos sobre os salários reais de equilíbrio nos outros setores.

A partir desta deterioração qualitativa do emprego pode-se imaginar uma maior atração relativa das atividades criminosas em comparação às atividades lícitas, agora menos atrativas, na média. Isto resultaria em piora nos níveis de criminalidade de equilíbrio, conforme sugerem os modelos teóricos apresentados no capítulo dois.

Feita esta digressão, fica incorporado à análise o aspecto qualitativo da deterioração relativa das condições de emprego no setor formal da economia, com a piora relativa do nível de emprego no setor industrial ao longo do período analisado.

Todas estas variáveis apresentadas até aqui estão vinculadas ao vetor renda e tratam das condições de renda e de emprego/desemprego (total e por setores econômicos).

Na tabela um há a evolução da média do Índice Paulista de Responsabilidade Social ${ }^{17}$ em suas diversas dimensões: renda, longevidade e educação. A dimensão renda é essencial na avaliação futura das condicionantes da criminalidade e da eficácia das políticas públicas, pois será uma das variáveis de controle utilizadas nos exercícios econométricos subseqüentes.

\footnotetext{
${ }^{17}$ O Índice Paulista de Responsabilidade Social é um indicador construído pela Fundação Seade para todos os municípios paulistas e é análogo ao indicador IDH (Índice de Desenvolvimento Humano) medido internacionalmente a partir de metodologia da PNUD e nos Censos brasileiros medidos pelo IBGE.
} 
TABELA 1

Índice Paulista de Responsabilidade Social

\begin{tabular}{lccc}
\hline \hline & IPRS renda & IPRS longeveidade & IPRS educação \\
\hline $\mathbf{1 9 9 7}$ & - & - & - \\
$\mathbf{1 9 9 8}$ & - & - & - \\
$\mathbf{1 9 9 9}$ & - & - & - \\
$\mathbf{2 0 0 0}$ & 41,8 & 66,2 & 42,3 \\
$\mathbf{2 0 0 1}$ & - & - & - \\
$\mathbf{2 0 0 2}$ & 34,4 & 67,9 & 52,3 \\
$\mathbf{2 0 0 3}$ & - & - & -
\end{tabular}

O segundo vetor de variáveis explicativas contempla condições sócio-demográficas $(S)$.

O vetor condições sócio-demográficas será aqui definido como $(S)$ e contém variáveis como: taxa de urbanização, densidade demográfica, população total do município e indicadores de responsabilidade social (IPRS), exceto em sua dimensão renda que já está incorporado no vetor $(R)$.

A dimensão renda já está contemplada à análise no vetor $(R)$. O fator educação é visto como um tratamento de longo prazo para a criminalidade por se refletir em maior custo de oportunidade futuro para o indivíduo cometer um crime, na medida em que mais educação leva a maior salário potencial, mantidos os demais fatores constantes.

A dimensão longevidade, por sua vez, tem sustentação em estudos que comprovam que os jovens são aqueles mais propensos a ingressar em atividades criminosas. Isto pode ser explicado por uma função de aversão ao risco positivamente relacionada com a idade do indivíduo. Ou seja, quanto mais jovem o indivíduo, mais propenso ao risco ele é, com declínio desta propensão conforme se reduz a expectativa residual de vida deste indivíduo. Dada uma punição para um tipo de crime, quanto mais velha for a pessoa, maior será o custo marginal desta pessoa ficar, por exemplo, durante dez anos presa, pois isto representará o resto de sua vida. Assim, o custo marginal é crescente na idade e com taxa de aceleração (segunda derivada) também crescente, o que explicaria teoricamente a menor incidência de criminosos mais velhos vis-à-vis criminosos jovens. 
A tabela 1 mostra que a dimensão renda foi aquela com pior desempenho no período analisado. Em contraposição, houve uma sensível melhora na dimensão Educação, em resposta às políticas públicas de universalização do acesso à educação ao longo deste período. Também ocorreu uma melhora progressiva do nível de expectativa da vida da população neste período, como reflexo de políticas preventivas de saúde pública e avanços da medicina.

Se forem consideradas outras dimensões da função utilidade de um indivíduo, adicionais à renda, inseridas no vetor $(S)$, pode-se ter um novo indício de deterioração nas condições sociais que expliquem uma maior busca por atividades criminosas.

Incrementos rápidos nas taxa de urbanização e maior densidade populacional representam potencial deterioração da qualidade de vida média da população, dadas as externalidades do crescimento desordenado dos municípios em termos de trânsito, poluição, condições precárias de moradia, etc. ${ }^{18}$ Tudo isto remete à redução na utilidade do indivíduo, independente da condição de renda deste indivíduo representativo. Esta piora, em conjunto com a deterioração qualitativa das condições do mercado de trabalho, aumenta a possibilidade de busca de retornos monetários em atividades criminosas. No arcabouço teórico já explicitado podemos incluir as dimensões educação, expectativa de vida e as demais variáveis vinculadas às condições sócio-demográficas dos municípios como variáveis que constituem o vetor estado $\mathrm{u}_{\mathrm{j}}$ definido para a função $\mathrm{O}_{\mathrm{j}}=\mathrm{O}_{\mathrm{j}}$ $\left(\mathrm{p}_{\mathrm{j}}, \mathrm{f}_{\mathrm{j}}, \mathrm{u}_{\mathrm{j}}\right)$, que define a função número de crimes no modelo apresentado por Becker (1968).

Outras variáveis que compõem o vetor $(S)$ e que podem explicar parcialmente o movimento de piora da criminalidade nos anos recentes estão vinculadas aos aumentos no grau de urbanização e na densidade populacional dos municípios paulistas. Municípios urbanos estão ligados, via de regra, a maior grau de desigualdade social. Diversos trabalhos apresentados na revisão de resultados empíricos trazem evidências de que a desigualdade é uma das maiores forças motrizes da piora da criminalidade, principalmente no que tange aos crimes contra o patrimônio.

\footnotetext{
${ }^{18}$ Vale dizer também que a migração é feita, em geral, por indivíduos insatisfeitos com suas condições precárias em outros municípios e que olham a condição média de outros municípios e vêem potencial de melhora. Assim, o ingressante marginal (migrante) tende a ter uma produtividade marginal mais baixa do que os já estabelecidos no município atrator, o que tende a puxar ao longo do tempo a média do município receptor para baixo deteriorando a renda média desta região ao longo do tempo.
} 
A maior densidade populacional, no mesmo sentido, permite um maior grau de contato social entre indivíduos e aumenta a probabilidade do indivíduo ter acesso a outros indivíduos com características diferenciadas, com mais/menos renda, mais/menos educação, mais/menos patrimônio. Com isto, ceteris paribus, é de se imaginar que maior densidade possa levar a maior taxa de criminalidade de equilíbrio ao aumentar a rede de relações sociais entre diferentes indivíduos e ampliar, portanto, o sentimento de desigualdade entre estes indivíduos.

EVOLUÇÃO DA TAXA DE URBANIZAÇÃO E DA DENSIDADE POPULACIONAL DOS MUNICÍPIOS PAULISTAS

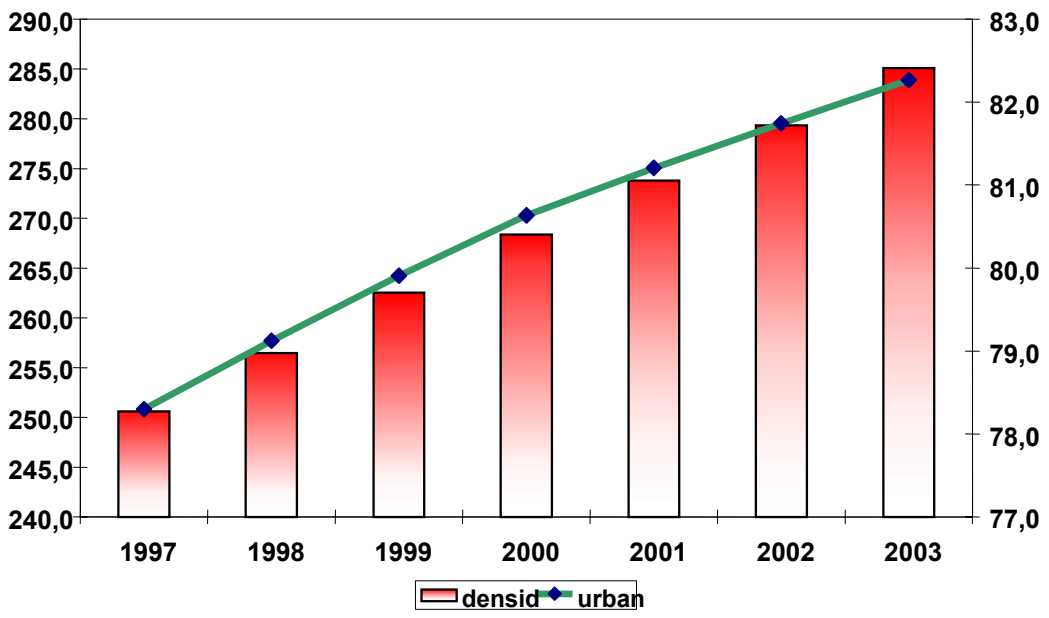

Há uma tendência natural ao aumento do grau de urbanização e da densidade demográfica dos municípios com a continuidade do fluxo migratório para cidades urbanas mais populosas, mas as taxas de variação têm apresentado redução na margem.

O terceiro vetor de variáveis está relacionado às condições das finanças públicas $(F)^{19}$.

$\mathrm{Na}$ ausência de variáveis diretamente observáveis que dêem a situação real de condições de habitação, educação e transporte, os dispêndios com previdência e custeio, com transporte, com

${ }^{19}$ Dados sobre finanças públicas são elaborados pela Fundação Seade através da Pesquisa Municipal Unificada - PMU. A PMU é uma pesquisa censitária que, bienalmente, percorre todos os municípios paulistas para coletar informações relevantes sobre gestão municipal. Investiga a capacidade organizacional, administrativa e financeira das prefeituras, além da realidade socioeconômica, cultural e urbana municipal, através de levantamentos realizados em todos os municípios do Estado. 
habitação e com educação, feitos anualmente pelos municípios, podem servir como informações complementares sobre os condicionantes da criminalidade. Mais do que isto, a avaliação de quais as variáveis que constam do vetor $(F)$ pode trazer resultados relevantes sobre quais as medidas, para além das medidas diretas de prevenção e repressão da segurança pública, são mais eficazes para minimizar a taxa de criminalidade de equilíbrio dos municípios.

Apresentadas as variáveis utilizadas nos testes empíricos para análise do comportamento da criminalidade são apresentados a seguir os resultados empíricos.

A análise subseqüente tenta captar quais as políticas de intervenção de segurança que se mostram efetivas para redução da criminalidade nos municípios que as adotaram. Nesta fase do trabalho inserem-se variáveis de intervenção (dummies) para identificar cada uma das diferentes políticas públicas implementadas em cada município e verifica-se o impacto para redução da criminalidade.

As principais políticas de segurança pública implementadas pelos municípios paulistas no período de análise e que são testadas são:

$$
\begin{aligned}
& 1 \text { - implantação de sistema Disque Denúncia } \\
& 20 \\
& \text { - adoção de sistema de Lei Seca } \\
& 3 \text { - implantação de Guarda Municipal }
\end{aligned}
$$

\footnotetext{
${ }^{20}$ O Disque-Denúncia é uma central comunitária de atendimento telefônico, destinada a receber informações da população sobre atividades criminosas e a transmiti-las aos órgãos de segurança pública. Suas atividades são mantidas com recursos provenientes de parcerias entre setores públicos e privados. Criado em agosto de 1995, o serviço vem ajudando as autoridades a combater o crime, contribuindo para integração entre cidadãos e sua polícia.
}

\footnotetext{
${ }^{21}$ A Lei Seca tem diferentes especificações entre os municípios, mas o escopo central é a restrição à venda de bebidas alcoólicas a partir de determinado horário com o fechamento dos bares. Estas medidas normalmente se concentram nos bairros mais violentos e visam reduzir homicídios por motivos fúteis.

${ }^{22}$ Atribuições da Guarda Municipal: 1 - Estabelecer as políticas, diretrizes e programas de Segurança Pública e Fiscalização do Trânsito, no que diz respeito a garantir o pleno exercício dos direitos e garantias fundamentais, individuais, coletivas, sociais e políticas e ainda a proteção dos bens, serviços e instalações municipais, estabelecidas nas Constituições Federal e Estadual e na Lei Orgânica Municipal. 2 - Articular e apoiar as ações de Segurança Pública desenvolvidas por Forças de Segurança Estadual e Federal dentro dos limites do Município. 3 - Contribuir para a prevenção e a diminuição da violência e da criminalidade, promovendo a
} 


\section{4 - implantação de Secretaria de Segurança Pública Municipal ${ }^{23}$}

Cada uma das políticas foi construída com objetivos específicos e se utiliza de instrumentos distintos para reduzir a criminalidade de equilíbrio em um município.

O Disque Denúncia é uma política que aumenta a probabilidade de um indivíduo que cometeu ato ilícito ser denunciado e de que este indivíduo cumpra pena. Isto se reflete, teoricamente, no modelo de Becker (1968), em aumento do coeficiente ligado à probabilidade do indivíduo ser pego e reduz o retorno esperado da atividade criminosa, com redução da criminalidade de equilíbrio neste sistema.

A Lei Seca tem como ponto focal a redução dos homicídios por motivos fúteis, ligados em grande parte ao consumo de álcool, conforme comprovado por análises que constataram que $85 \%$ dos autores e $75 \%$ das vítimas de homicídios estavam intoxicadas durante o crime (estudo realizado em Memphis no Tenesse). Outro estudo resume 331 estudos médicos entre os anos 1975 e 1995 e aponta que exames para presença de álcool são positivos em 29\% dos suicídios, 38,5\% dos homicídios culposos e 41\% dos homicídios dolosos (Annals of Emergency Medicine 33(6): 659-668 (1999)). Em Cotrim e Duarte (2000) há uma análise de caso em Curitiba que mostra que $58,9 \%$ dos autores e 53,6\% das vítimas de 130 homicídios ocorridos entre 1990 e 1995 estavam sob efeito de álcool. Visto de outra forma, em 76,2\% dos 130 casos de homicídios, ou a vítima, ou o autor do homicídio, ou ambos, estavam sob efeito de álcool. É sob este diagnóstico, portanto, que a Lei Seca é constituída e espera-se que tenha efeito mais específico em redução dos homicídios do que em relação a outros crimes.

mediação de conflitos e o respeito aos direitos fundamentais dos cidadãos. 4 - Prevenir e inibir atos delituosos que atentem contra os bens e serviços e instalações municipais, priorizando a segurança escolar. 5 - Estabelecer parcerias com órgãos estaduais e da União, por meio de celebração de convênios, com vistas a implementação de ações policiais integradas e preventivas.

${ }^{23}$ As Secretarias Municipais de Segurança Pública são criadas por intermédio da Lei Municipal com a responsabilidade de garantir, a nível local, a existência de condições para atuação de mecanismos voltados à segurança de bens, serviços e instalações municipais, bem como o planejamento e a execução de medidas de proteção à população em caso de eventos desastrosos que ocorram no território municipal. 
A implementação de políticas repressivas de segurança, como Guarda Municipal e criação de Secretaria de Segurança Pública Municipal, deve aumentar a incerteza do criminoso em relação à probabilidade de apreensão, por mais que estas instituições não tenham poder de polícia de fato, restrito às polícias civil e militar. Assim, servem como políticas inibidoras e que, em tese, concorrem para redução da criminalidade de equilíbrio do sistema. 


\section{Condicionantes da criminalidade.}

O esforço inicial constituiu na montagem de uma base de dados, com as variáveis mensuradas per capita, para viabilizar a análise empírica deste trabalho. Estes ajustes foram necessários para variáveis como: número de crimes e total de empregos, por exemplo. Além disto, houve a normalização das variáveis financeiras (arrecadação e gastos governamentais nos diferentes setores sociais) com o deflacionamento pelo IPC-FIPE (índice de inflação diretamente mensurado em São Paulo) e também com a normalização pela população de cada município. Colocado o esforço inicial, na tabela dois são apresentadas todas as variáveis que foram utilizadas para concepção dos diferentes modelos de estimação. As variáveis estão divididas essencialmente nos três vetores já apresentados no capítulo anterior, a saber:

1 - Vetor Renda $(R)$ : variáveis relacionadas às condições de renda e ao mercado formal de trabalho

2 - Vetor Sócio-Demográfico (S): variáveis relacionadas com as condições sócioeconômicas e demográficas de cada município

3 - Vetor Finanças Públicas $(F)$ : variáveis relacionadas com a alocação dos dispêndios do setor público e volume de recursos destinados aos diferentes programas públicos.

A compatibilização destes vetores com o arcabouço teórico apresentado em Ehrlich (1973) tem no Vetor $(R)$ as variáveis relacionadas à taxa de retorno da atividade no mercado formal. $\mathrm{O}$ retorno da atividade ilegal está de forma indireta relacionado com condições sócio-demográficas da região. Municípios de maior densidade demográfica, por exemplo, favorecem maior contato entre classes de diferente renda (maior sentimento de desigualdade), municípios com mais bens e mais riqueza disponível elevam o retorno médio do crime contra o patrimônio, entre outros fatores.

Por fim, o vetor de variáveis de estado, contemplado no modelo teórico, está presente com variáveis como taxa de urbanização do município, indicador IPRS (exceto dimensão riqueza incorporada ao vetor $(\mathrm{R}))$, entre outras variáveis. 
A tabela dois relaciona todas as variáveis explicativas constantes da parte empírica e mostra para quais períodos (anos) há disponibilidade de dados para cada uma das variáveis (caracteriza bem a formação do painel desbalanceado).

Tabela 2

\begin{tabular}{cccccccc}
\hline \multicolumn{7}{c}{ Levantamento da distribuição das variáveis ano a ano } \\
\hline \hline densidade & 1997 & 1998 & 1999 & 2000 & 2001 & 2002 & 2003 \\
urbanização & tem & tem & tem & tem & tem & tem & tem \\
despesa total & tem & tem & tem & tem & tem & tem & tem \\
despesa educação & tem & tem & tem & tem & tem & & \\
despesa habitação & tem & tem & tem & tem & tem & & \\
despesa transporte & tem & tem & tem & tem & tem & & \\
população total & tem & tem & tem & tem & tem & tem & tem \\
despesa com pessoal & tem & tem & tem & tem & tem & & \\
emprego total & tem & tem & tem & tem & tem & tem & tem \\
emprego industrial & tem & tem & tem & tem & tem & tem & tem \\
despesa previdência & tem & tem & tem & tem & tem & & \\
IPRS renda & & & & tem & & tem & \\
IPRS longeveidade & & & & tem & & tem & \\
IPRS educação & & & & tem & & tem &
\end{tabular}

As estimações estão divididas em duas fases. Cada uma das fases está contemplada em um capítulo. Neste capítulo comparamos as condicionantes que concorrem para maior taxa de criminalidade em determinados municípios sob diversas especificações. No capítulo cinco, por sua vez, são testadas as efetividades das diferentes políticas públicas de segurança para o controle dos dois diferentes tipos de crimes (patrimoniais e homicídios dolosos). 


\section{1 - Características da violência com base nos vetores propostos.}

Para esta fase é utilizado o conjunto de variáveis explicativas apresentado na tabela dois e que podem ser dividas entre os três vetores previamente estabelecidos com a seguinte tipologia e nomenclatura das variáveis:

1 - Vetor Renda $(R)$ :

IPRS-renda = Índice Paulista de Responsabilidade Social - Renda (indicador análogo ao IDH medido pelo Seade)

Emprego total $=$ emprego total no município apurado pelo Ministério do Trabalho pela pesquisa Caged. Serve como medida de emprego/desemprego e, em conjunto com a dimensão renda, dá uma medida indireta de desigualdade de renda no município.

2 - Vetor Sócio-Demográfico $(S)$ :

IPRS-Educação = Índice Paulista de Responsabilidade Social - Educação (indicador análogo ao IDH medido pelo Seade)

IPRS-Longevidade $=$ Índice Paulista de Responsabilidade Social - Longevidade (indicador análogo ao IDH medido pelo Seade)

População = população total do município

Urbanização $=$ taxa de urbanização do município

Densidade $=$ Densidade populacional do município

3 - Vetor Finanças Públicas $(F)$ :

Despesa pessoal $=$ despesa per capita com folha de pagamento e benefícios. 
Despesa transporte $=$ despesa per capita com setor de transporte

Despesa habitação $=$ despesa per capita com setor de habitação

Despesa total $=$ despesa per capita total do município

Nesta fase do trabalho, após a montagem dos dados sob a forma de painel, dois estimadores de painel são utilizados para estimar os modelos: estimador de efeito fixo e estimador de efeito aleatório. Assim será possível testar hipóteses que permitam discriminar as variáveis que melhor caracterizam a violência nos municípios paulistas.

É feita a comparação entre as estimações por efeito fixo e efeito aleatório, além da comparação com a estimativa que incorpora a própria variável dependente defasada como explicativa para criminalidade presente, justificada pela condição inercial da violência capturada em diversos trabalhos.

Vale a ressalva de que a estimação feita com a simples inserção da variável dependente, e não a estimação por GMM (método Generalizado dos Momentos), que requer a utilização de instrumentos, não corrige as estruturas de correlação serial dos erros como o método sugerido por Arellano e Bond (1989), conforme explicitado em Kume (2004), que minimiza problema de endogeneidade e reduz efeito de autocorrelação serial dos erros e suas implicações sobre os estimadores.

Apesar desta restrição, adicionar a variável dependente nos permite comparar os resultados com as estimações por efeito fixo e aleatório e avaliar a consistência entre as diferentes estimações.

Na estimação por efeito aleatório há a hipótese de que os termos não observáveis $\left(\mathrm{a}_{\mathrm{i}}\right)$, tais como: alocação de policiais civis e militares por município (que depende no caso brasileiro do governo estadual e varia ao longo do tempo) e outras características dos municípios não contempladas nos vetores de características sócio-demográficas e no vetor finanças públicas, são não correlacionados com nenhuma variável que consta de nosso vetor de variáveis explçicativas $\mathrm{X}_{\mathrm{i}}$. 
Esta hipótese pode ser representada formalmente como:

$\mathrm{Y}_{\mathrm{it}}=\beta_{0}+\beta_{1} \mathrm{X}_{\mathrm{it} 1}+\ldots+\beta_{\mathrm{k}} \mathrm{X}_{\mathrm{itk}}+\mathrm{a}_{\mathrm{i}}+\mathrm{u}_{\mathrm{it}}$,

onde $\operatorname{cov}\left(\mathrm{X}_{\mathrm{itj}}, \mathrm{a}_{\mathrm{i}}\right)=0, \quad \mathrm{t}=1,2, \ldots, \mathrm{T} ; \mathrm{j}=1,2, \ldots, \mathrm{k}$

Com a validação da hipótese acima o estimador poderia ser obtido de forma consistente apenas rodando um OLS pooled, entretanto não seria considerada a característica de correlação temporal do resíduo composto $v_{i t}=a_{i}+u_{i t}$, obtida pelo simples fato de $a_{i}$ estar fixo no tempo. Com isto terse-á a estimação de erro padrão errado (sobre dimensionado) para os estimadores, o que pode levar a conclusão equivocada a respeito dos testes de hipótese e de sua significância estatística nos modelos estimados. São apresentados a seguir os resultados das estimações por efeito aleatório.

\begin{tabular}{lcccc}
\multicolumn{5}{c}{ Tabela 3 } \\
\hline \multicolumn{5}{c}{ Estimação por Efeito Aleatório } \\
\hline \hline crime patrimonial & Coeficiente & Erro Padrão & Teste t & $\mathrm{P}>|\mathrm{t}|$ \\
\hline iprs educação & $-5,199$ & 1,212 & $-4,290$ & 0.000 \\
iprs longeveidade & $-0,257$ & 1,034 & $-0,250$ & 0.804 \\
iprs renda & 6,480 & 1,035 & 6,260 & 0.000 \\
emprego total & 2,481 & 1,134 & 2,190 & 0.029 \\
despesa pessoal & $-5,193$ & 0,485 & $-10,720$ & 0.000 \\
população & 0,000 & 0,000 & 3,580 & 0.000 \\
despesa transporte & $-0,939$ & 0,236 & $-3,990$ & 0.000 \\
despesa habitação & $-0,765$ & 0,191 & $-4,010$ & 0.000 \\
despesa total & 0,127 & 0,036 & 3,510 & 0.000 \\
urbanização & 22,934 & 1,580 & 14,520 & 0.000 \\
densidade & 0,067 & 0,025 & 2,700 & 0.007 \\
constante & $-255,580$ & 130,199 & $-1,960$ & 0.050
\end{tabular}

Não há evidências a priori suficientes para garantir que as variáveis omitidas e/ou as variáveis não observáveis do modelo não estejam correlacionadas com as variáveis explicativas que se mostraram significantes para o modelo de efeito aleatório. Sendo assim, é necessário que se faça a estimação do modelo de efeito fixo.

A hipótese de efeito fixo a respeito dos termos não observáveis é de que eles podem ser correlacionados com as variáveis explicativas. Como estas características não variam no tempo, segundo as hipóteses de efeito fixo, (vizinhança com outros municípios violentos e presença de 
prisões no município, por exemplo, não variam), quando se tira o efeito fixo desaparecem os efeitos destas variáveis e não há viés nos coeficientes estimados.

Para o caso do modelo de efeito fixo, o que se tem como hipótese central está resumido abaixo:

$\mathrm{Y}_{\mathrm{it}}=\beta_{0}+\beta_{1} \mathrm{X}_{\mathrm{it} 1}+\ldots+\beta_{\mathrm{k}} \mathrm{X}_{\mathrm{itk}}+\mathrm{a}_{\mathrm{i}}+\mathrm{u}_{\mathrm{it}}$, (tal qual a formulação para efeito aleatório).

O termo $a_{i}$, entretanto, é visto como um efeito não observável que é particular para cada município (i), mas que não varia ao longo do tempo. Daí esta variável também ser denominada: efeito fixo. $\mathrm{O}$ termo $\mathrm{a}_{\mathrm{i}}$, portanto, está vinculado à heterogeneidade não observada dos municípios e que são fixas no tempo de análise (sete anos), tais como: região onde está localizado, com qual município faz fronteira, abriga ou não penitenciárias, clima, religiosidade da população, entre outras características que não são diretamente observadas, mas que influenciam na probabilidade do município ter maiores taxas de criminalidade.

Se as características não observáveis que constam de $\mathrm{a}_{\mathrm{i}}$ tiverem correlação com $\mathrm{X}_{\mathrm{it}}$, então estimar um modelo por efeito aleatório, como feito na tabela três, gera coeficientes viesados em virtude do efeito de viés de heterogeneidade (viés causado por omissão de variável constante no tempo).

Uma forma de eliminar este viés potencial é tirar a primeira diferença das variáveis e estimar o modelo a partir deste modelo alterado para:

$\Delta \mathrm{Y}_{\mathrm{it}}=\beta_{1} \Delta \mathrm{X}_{\mathrm{it} 1}+\ldots+\beta_{\mathrm{k}} \Delta \mathrm{X}_{\mathrm{itk}}+\Delta \mathrm{a}_{\mathrm{i}}+\Delta \mathrm{u}_{\mathrm{it}}$, onde $\Delta=\mathrm{Z}_{\mathrm{it}}-\mathrm{Z}_{\mathrm{it}-1}$

$\mathrm{E}$, como $\mathrm{a}_{\mathrm{i}}$ não varia no tempo, tal qual a constante, estes termos desaparecem e estima-se então, por OLS (agora sem qualquer problema de viés dos estimadores) o seguinte modelo modificado:

$\Delta \mathrm{Y}_{\mathrm{it}}=\beta_{1} \Delta \mathrm{X}_{\mathrm{it} 1}+\ldots+\beta_{\mathrm{k}} \Delta \mathrm{X}_{\mathrm{itk}}+\Delta \mathrm{u}_{\mathrm{it}}$, onde $\Delta=\mathrm{Z}_{\mathrm{it}}-\mathrm{Z}_{\mathrm{it}-1}$

Estes resultados alternativos ao modelo de efeito aleatório estão apresentados nas tabelas quatro (sem variável explicativa desasada) e cinco (com variável explicativa defasada), que trazem as 
estimações por efeito fixo. Estas estimações trazem indícios de que há de fato uma componente inercial nos níveis de crime contra o patrimônio, mas os coeficientes estimados estão sujeitos a vieses por não haver a correção da estrutura de autocorrelação dos resíduos.

Tabela 4

\begin{tabular}{lcccc}
\hline \multicolumn{5}{c}{ Estimação por Efeito Fixo } \\
\hline \hline crimepatrim & Coeficiente & Erro Padrão & Teste t & $\mathrm{P}>|\mathrm{t}|$ \\
\hline iprs educação & $-4,680$ & 1,180 & $-3,966$ & 0.000 \\
iprs longeveidade & 0,419 & 1,013 & 0,414 & 0.679 \\
iprs renda & 4,500 & 1,016 & 4,429 & 0.000 \\
emprego total & 0,333 & 1,270 & 0,262 & 0.793 \\
despesa pessoal & $-4,626$ & 0,498 & $-9,289$ & 0.000 \\
população & 0,003 & 0,001 & 4,403 & 0.000 \\
despesa transporte & $-0,525$ & 0,237 & $-2,214$ & 0.027 \\
despesa habitação & $-0,778$ & 0,190 & $-4,096$ & 0.000 \\
despesa total & 0,108 & 0,036 & 2,998 & 0.003 \\
urbanização & 31,915 & 3,643 & 8,759 & 0.000 \\
densidade & 0,083 & 0,125 & 0,670 & 0.503 \\
constante & $-1.150,914$ & 304,985 & $-3,774$ & 0.000
\end{tabular}

Tabela 5

\begin{tabular}{lcccc}
\hline \multicolumn{4}{c}{ Estimação por Efeito Fixo com Dependente Defasada } \\
\hline \hline crimepatrim & Coeficiente & Erro Padrão & Teste t & $\mathrm{P}>|\mathrm{t}|$ \\
\hline iprs educação & $-3,247$ & 1,058 & $-3,070$ & 0,002 \\
iprs longeveidade & 1,355 & 0,903 & 1,500 & 0,134 \\
iprs renda & $-0,444$ & 0,919 & $-0,480$ & 0,629 \\
emprego total & $-0,323$ & 1,133 & $-0,290$ & 0,776 \\
despesa pessoal & $-1,532$ & 0,455 & $-3,370$ & 0,001 \\
população & 0,000 & 0,001 & $-0,030$ & 0,977 \\
despesa transporte & 0,076 & 0,212 & 0,360 & 0,720 \\
despesa habitação & $-0,106$ & 0,171 & $-0,620$ & 0,533 \\
despesa total & $-0,083$ & 0,033 & $-2,550$ & 0,011 \\
urbanização & 8,468 & 3,330 & 2,540 & 0,011 \\
densidade & $-0,096$ & 0,111 & $-0,870$ & 0,387 \\
crime defasado & 0,276 & 0,009 & 31,640 & 0,000 \\
constante & 616,199 & 277,468 & 2,220 & 0,026
\end{tabular}

A tabela seis traz uma ilustração resumo que compara os coeficientes estimados para as mesmas variáveis explicativas, uma a uma, entre as três estimações. Destaca-se que a inserção da variável dependente defasada capturou parte dos efeitos de algumas variáveis explicativas que nas duas estimações alternativas se mostraram significativas e com sinal coerente. Como se pode observar há relativa similaridade entre os resultados das estimações por efeito fixo e por efeito aleatório $(\text { sem defasada como explicativa })^{24}$.

\footnotetext{
${ }^{24}$ A especificação formal do teste de Hausman está no apêndice com a descrição das hipóteses que são testadas no caso particular da contraposição entre estimadores por efeito fixo e efeito aleatório.
} 
Tabela 6

\begin{tabular}{l|rr|rr|rr|}
\hline \multicolumn{7}{|c|}{ Comparação entre coeficientes estimados } \\
\hline & \multicolumn{2}{|c|}{ efeito fixo } & \multicolumn{2}{c|}{ efeito fixo com defasada } & \multicolumn{2}{c|}{ efeito aleatório } \\
\hline & coeficiente & desvio padrão & coeficiente & desvio padrão & coeficiente & \multicolumn{1}{c|}{ desvio padrão } \\
\hline iprs educação & $-4,68$ & 1,18 & $-3,25$ & 1,06 & $-5,20$ & 1,21 \\
iprs longeveidade & 0,42 & 1,01 & 1,35 & 0,90 & $-0,26$ & 1,03 \\
iprs renda & 4,50 & 1,02 & $-0,44$ & 0,92 & 6,48 & 1,03 \\
emprego total & 0,33 & 1,27 & $-0,32$ & 1,13 & 2,48 & 1,13 \\
despesa pessoal & $-4,63$ & 0,50 & $-1,53$ & 0,45 & $-5,19$ & 0,48 \\
população & 0,00 & 0,00 & 0,00 & 0,00 & 0,00 & 0,00 \\
despesa transporte & $-0,52$ & 0,24 & 0,08 & 0,21 & $-0,94$ & 0,24 \\
despesa habitação & $-0,78$ & 0,19 & $-0,11$ & 0,17 & $-0,77$ & 0,19 \\
despesa total & 0,11 & 0,04 & $-0,08$ & 0,03 & 0,13 & 0,04 \\
urbanização & 31,91 & 3,64 & 8,47 & 3,33 & 22,93 & 1,58 \\
densidade & 0,08 & 0,12 & $-0,10$ & 0,11 & 0,07 & 0,02 \\
constante & $-1150,91$ & 304,98 & 616,20 & 277,47 & $-255,58$ & 130,20 \\
crime defasado & & & 0,28 & 0,01 & &
\end{tabular}

No teste conjunto dos coeficientes (entre efeito aleatório e efeito fixo sem dependente defasada) há evidências de diferença conjunta substancial entre coeficientes (teste de Hausman). Ou seja, rejeita-se a hipótese nula (Ho) de que os coeficientes são estatisticamente iguais com uma estatística CHI2 (8) $=101,97$ que implica Prob $>$ Chi2 $=0.0000$.

O teste de Hausman, descrito no item um do Apêndice, confirma que há evidência de diferenças estatísticas dos coeficientes estimados entre efeito fixo e efeito aleatório, o que implica que o modelo de efeito fixo é o mais adequado entre estas duas formulações, por ser consistente sob a hipótese alternativa, diferentemente dos estimadores de efeito aleatório. Assim, confirma-se a tendência de modelos que consideram localidades que têm determinadas características não observáveis (ou não quantificáveis) que não se alteram no tempo, mas que estão de alguma forma relacionadas com as variáveis explicativas, requererem estimações por efeito fixo como forma de gerar estimadores consistentes.

As variáveis que são permanentemente significativas a pelo menos $5 \%$ de significância em todos os modelos e com coeficientes com sinal consistente, o que sinaliza robustez dos resultados para estas variáveis, são: IPRS-Educação (com mais educação levando a menos criminalidade), Despesa com Pessoal (com maior transferência direta de renda do estado concorrendo para menos incentivo ao crime), população total (municípios mais populosos estão sujeitos a mais crimes patrimoniais) e taxa de urbanização (municípios mais urbanizados são associados à maior incidência de crimes contra patrimônio). Os sinais destes coeficientes estimados são coerentes 
com outros trabalhos empíricos nacionais e internacionais, e trazem indícios de que o fenômeno de crescente criminalidade está associado aos municípios mais populosos e mais urbanizados e que tratamentos, como melhora de nível educacional e maior renda disponível para população, tendem a ter efeitos positivos para conter a violência.

Adicionalmente às estimações de painel desbalanceado foi estimada uma regressão em cross section para o ano de $2000 \mathrm{com}$ as mesmas variáveis explicativas. A seleção do ano 2000 se justifica por ser este o único ano da amostra em que todas as variáveis explicativas têm mensuração concomitante. A avaliação dos resultados da cross section feita para o ano de 2000 reforça a robustez deste conjunto de variáveis explicativas, na medida em que os sinais e a significância estatística das variáveis não se alteram de forma substancial, conforme demonstrado abaixo.

Tabela 7

\begin{tabular}{lcccc}
\hline \hline \multicolumn{5}{c}{ Cross Section para o ano 2000 } \\
\hline crimepatrim & Coeficiente & Erro Padrão & Teste t & $\mathrm{P}>|\mathrm{t}|$ \\
\hline iprs educação & $-8,203$ & 3,403 & $-2,410$ & 0,016 \\
iprs longeveidade & $-10,461$ & 3,390 & $-3,090$ & 0,002 \\
iprs renda & 49,550 & 3,279 & 15,110 & 0,000 \\
emprego total & $-3,353$ & 2,385 & $-1,410$ & 0,160 \\
despesa pessoal & $-2,799$ & 2,649 & $-1,060$ & 0,291 \\
população & 0,000 & 0,000 & 1,950 & 0,051 \\
despesa transporte & $-2,708$ & 0,785 & $-3,450$ & 0,001 \\
despesa habitação & $-0,823$ & 0,610 & $-1,350$ & 0,178 \\
despesa total & 0,208 & 0,109 & 1,900 & 0,058 \\
urbanização & 3,269 & 2,263 & 1,440 & 0,149 \\
densidade & $-0,020$ & 0,027 & $-0,720$ & 0,471 \\
constante & 410,749 & 277,418 & 1,480 & 0,139
\end{tabular}

A comparação entre os resultados obtidos nas diferentes estimações, que variam de painel com efeitos fixo, painel por efeito aleatório e cross section para o ano 2000 trazem resultados coerentes e sustentam a robustez dos resultados obtidos, a menos para estimação com a variável dependente defasada, que está sujeita a viés por não correção de estrutura de autocorrelação temporal dos resíduos.

Assim, há evidências de que municípios com melhores condições educacionais (representadas pelo IPRS-educação) estão sujeitos a menores níveis de criminalidade de equilíbrio. No mesmo 
sentido, municípios com média etária da população mais avançada (medida pelo IPRSlongevidade) tendem a ter menor incidência de crimes patrimoniais (no caso da estimação da cross section para o ano 2000), comprovando o fato estilizado de que crimes são cometidos em sua maior parcela por indivíduos mais jovens, a quem está associada menor aversão ao risco.

Por outro lado, municípios com maior renda média atraem mais criminalidade, até por conta de terem maior disponibilidade (menor restrição de oferta de bens) de patrimônio a ser afetado por criminalidade (com exceção da estimativa do painel com efeito fixo e com crime patrimonial defasado em um período adicionado como variável explicativa).

As variáveis ligadas às finanças públicas trazem sinais interessantes. Não é um município que simplesmente gasta mais que leva a menor nível de criminalidade. Pelo contrário, municípios que gastam mais por habitante estão sujeitos a maior criminalidade. Gastos maiores dos municípios têm de ter como contrapartida intertemporal arrecadação maior e, portanto, retenção maior de renda da população em tributos e contribuições. Gastos municipais elevados estão associados, no limite, à perda de renda disponível da população. Isto se reflete em menor preço sombra para contrabalancear retorno das atividades criminosas que são, por definição, insensíveis ao regime de tributação.

Por outro lado, controlados pelos dispêndios totais do município por habitante, aumentos de gastos com benefícios sociais diretos são indutores de menor criminalidade. Assim, mais gastos com transporte, habitação e pessoal aparecem como fontes que levam à queda de criminalidade por gerarem aumento de bem estar da população, reduzindo incentivo à opção por atividades criminosas.

Por fim, as características sócio-demográficas que são condizentes com maiores taxas de criminalidade comprovam mais um fato estilizado das discussões acerca da violência no Brasil. A criminalidade está associada aos municípios mais populosos, mais urbanizados e com maior densidade demográfica. Estas características, em conjunto, são compatíveis com os grandes centros urbanos. Os centros urbanos se caracterizam por concentrarem boa parte da população, com alta taxa de migração, concentrada em população jovem em busca de oportunidade. Como 
resultado deste movimento migratório descoordenado os grandes centros urbanos estão sujeitos a processos de crescimento urbano desordenado que geram ambientes mais propícios para emergir violência.

Nas estimações dos mesmos modelos para explicação de homicídio doloso não se apresentaram como estatisticamente relevantes as variáveis de estado. Desta forma trataremos apenas adiante os efeitos das diferentes políticas públicas para contenção dos homicídios, não havendo indícios de que as variáveis de estado expliquem diferentes níveis deste crime entre municípios. Estes crimes podem estar ligados, portanto, mais a fatores não observáveis, como consumo de bebidas alcoólicas e acesso a armas de fogo, do que os crimes patrimoniais. 


\section{Efeito das intervenções de segurança pública.}

Ao longo dos últimos anos, principalmente a partir da segunda metade dos anos noventa e no princípio da atual década, foram concebidas várias políticas de segurança pública municipais para lidar com o movimento de aumento da criminalidade nos municípios paulistas.

São testados, nesta parte do trabalho, após a avaliação dos condicionantes da criminalidade feita no capítulo anterior, quais os efeitos sobre as taxas de criminalidade que as implantações das diferentes políticas de segurança implicaram para os municípios que as adotaram. Para tanto são avaliados os estimadores de diferença-em-diferença para avaliar o efeito de cada uma das políticas para redução de crimes patrimoniais e de homicídios dolosos. Foram feitos testes de hipóteses independentes para os efeitos de cada uma das políticas sob duas formulações:

1 - SEM a inserção de outras variáveis de controle

2 - COM a inserção de outras variáveis de controle

Foram mapeadas, através das publicações de todos os relatórios recentes da Secretaria de Segurança Pública do Estado de São Paulo e de suas bases de dados, todas as ocorrências para as diferentes políticas de segurança nos municípios paulistas. Assim, há a criação de variáveis de intervenção (dummies) para as diferentes políticas de segurança de forma que se possam separar o conjunto de municípios tratados do conjunto de municípios de controle para cada uma das políticas. A partir desta separação cria-se uma dummy para cada uma das políticas que reportará.

0 - caso municípios NÃO tenha executado determinada política (controle)

1 - caso município tenha executado política (tratado)

Em Kahn e Zanetic (2005) há todo o levantamento das datas em que as diferentes políticas de segurança foram implantadas para cada município paulista, com uma discussão relevante do papel dos municípios para segurança pública no Brasil. Estes autores utilizam uma base de dado diferenciada da empreendida neste trabalho e fazem uma análise em séries de tempo, com análise 
de quebras estruturais para avaliar o efeito das diferentes políticas de segurança para redução de determinados crimes nos municípios que implantaram estas políticas.

As políticas de segurança que são testadas, individualmente, são:

1 - implantação do sistema de Disque Denúncia no município.

2 - aprovação de Lei Municipal que restringe o funcionamento de bares e vendas de bebidas alcoólicas em determinadas regiões mais violentas, ou em todas as regiões do município.

3 - institucionalização de Secretaria de Segurança Pública Municipal.

4 - implementação da Guarda Municipal preventiva, sem a premissa de poder de polícia que é exclusiva das polícias civil e militar na legislação brasileira.

A formulação dos testes empíricos para estimação dos estimadores de diferença-em-diferença foi feita de forma homogênea para as diferentes políticas. Assim, optou-se para análise da eficiência das políticas pela utilização de dados em pooled cross section para dois períodos (1997 e 2003).

A estipulação dos dois períodos limites se justifica por conseguirmos assim separar, um período onde não havia tratamento de nenhum município (1997), do período em que há maior número de municípios tratados (2003). Além disto, as demais variáveis de controle têm uma variância maior do que se estipulássemos dois períodos muito próximos.

A idéia para avaliação das políticas foi separar duas cross section (1997 e 2003) coletadas antes e depois dos eventos (execução das diferentes políticas) para determinar o efeito sobre as taxas de criminalidade (crimes patrimoniais e homicídios dolosos).

A expressão formal para os testes empíricos para os estimadores de diferença-em-diferença pode ser feita da seguinte forma: 
Consideraremos sempre dois grupos, a partir das variáveis chamadas: disque denuncia, guarda municipal, Lei Seca e $S S P^{25}$, que separam os grupos de municípios tratados para cada uma das políticas dos grupos de municípios que servem de controle.

Além disto, foi criada uma dummy de tempo, denominada dummy ano, que separa o ano de 1997, quando os municípios tratados ainda não eram objetos das políticas de segurança, e o ano de 2003, quando os municípios tratados já haviam implantado as políticas de segurança.

$\begin{array}{lllll}\text { Dummy ano } & = & 0 & - & \text { para } 1997 \\ & = & 1 & - & \text { para } 2003\end{array}$

Assim, cada município tratado terá sempre duas observações, uma referente ao período prétratamento e outra referente ao período pós-tratamento.

As estimações podem ser expressas formalmente como:

$\mathrm{Y}_{\mathrm{i}}=\alpha+\beta^{*}$ dummy tratamento $_{\mathrm{i}}+\gamma^{*}$ dummy ano $_{\mathrm{i}}+\delta^{*}\left(\right.$ dummy tratamento $_{\mathrm{i}}^{*}$ dummy ano $\left._{\mathrm{i}}\right)+\varepsilon_{\mathrm{i}}(5.1)$

Onde todos os parâmetros $\alpha, \beta, \gamma, \delta$ são desconhecidos e $\varepsilon_{\mathrm{i}}$ é um termo aleatório, erro não observável que contém todos os determinantes de $\mathrm{Y}_{\mathrm{i}}$ que nosso modelo eventualmente omita. A interpretação individual para cada um dos termos estimados é como segue:

$\alpha=$ termo constante

$\beta=$ efeito específico relacionado ao grupo de tratamento (que contabiliza para média da diferença permanente entre municípios tratados e controle).

$\gamma=$ tendência temporal comum aos grupos de municípios tratados e de controle

$\delta=$ efeito real do tratamento (estimador de diferença-em-diferença)

\footnotetext{
${ }^{25}$ Onde disque denuncia refere-se aos municípios tratados com Disque Denúnica, guarda municipal refere-se aos municípios tratados com Guarda Municipal, Lei Seca refere-se aos municípios tratados com Lei Seca e SSP refere-se aos municípios tratados com Secretaria de Segurança Pública Municipal
} 
Um critério razoável para afirmar que um estimador é bom é ele ser não viesado, o que implica que na média o estimador acerta, ou matematicamente que o valor esperado do estimador:

$$
\mathrm{E}\left[\delta^{\prime}\right]=\delta
$$

As hipóteses que nós precisamos para que o estimador de diferença-em-diferença esteja correto são dadas por:

1 - o modelo especificado em 5.1 esteja corretamente especificado. Por exemplo, a estrutura aditiva do modelo seja adequada.

2 - o termo de erro tenha média zero: $\mathrm{E}\left[\varepsilon_{\mathrm{i}}\right]=0$. Esta não é uma hipótese forte com a inserção da constante na regressão.

3 - o termo de erro seja não correlacionado com as outras variáveis explicativas da equação

$\operatorname{Cov}\left(\varepsilon_{\mathrm{i}}\right.$, dummy tratamento $\left._{\mathrm{i}}\right)=0$

$\operatorname{Cov}\left(\varepsilon_{\mathrm{i}}\right.$, dummy $\left.a n o_{\mathrm{i}}\right)=0$

$\operatorname{Cov}\left(\varepsilon_{\mathrm{i}}\right.$, dummy ano $_{\mathrm{i}}^{*}$ dummy tratamento $\left._{\mathrm{i}}\right)=0$

Sendo a última hipótese geralmente a mais crítica.

Sob estas hipóteses podemos inclusive determinar os valores esperados das médias condicionais dos diferentes grupos nos diferentes períodos a partir dos coeficientes estimados como sendo:

$$
\begin{aligned}
& \mathrm{E}\left[\mathrm{Y}_{0}{ }^{\mathrm{T}}\right]=\alpha+\beta \\
& \mathrm{E}\left[\mathrm{Y}_{1}{ }^{\mathrm{T}}\right]=\alpha+\beta+\gamma+\delta \\
& \mathrm{E}\left[\mathrm{Y}_{0}{ }^{\mathrm{C}}\right]=\alpha \\
& \mathrm{E}\left[\mathrm{Y}_{1}{ }^{\mathrm{C}}\right]=\alpha+\gamma
\end{aligned}
$$

O estimador de diferença-em-diferença (ou de dupla diferença) é definido como a diferença da média do grupo de tratamento antes e depois do tratamento, menos a diferença da média do grupo de controle antes e depois do período de tratamento. Isto significa literalmente uma diferença-da-diferença das médias amostrais dos dois grupos em dois períodos distintos (pré e pós-tratamento). 


$$
\delta_{\mathrm{DD}}=\breve{\mathrm{y}}_{1}{ }^{\mathrm{T}}-\breve{\mathrm{y}}_{0}{ }^{\mathrm{T}}-\left(\breve{\mathrm{y}}_{1}{ }^{\mathrm{C}}-\breve{\mathrm{y}}_{0}{ }^{\mathrm{C}}\right)
$$

O que, se tirarmos as esperanças dos estimadores, levará a um estimador não viesado de $\delta$

$$
\begin{aligned}
\delta_{\mathrm{DD}} & =\mathrm{E}\left[\breve{\mathrm{y}}_{1}{ }^{\mathrm{T}}\right]-\mathrm{E}\left[\breve{\mathrm{Y}}_{0}{ }^{\mathrm{T}}\right]-\left(\mathrm{E}\left[\breve{\mathrm{Y}}_{1}^{\mathrm{C}}\right]-\mathrm{E}\left[\breve{\mathrm{Y}}_{0}{ }^{\mathrm{C}}\right]\right) \\
& =\alpha+\beta+\gamma+\delta-(\alpha+\beta)-(\alpha+\gamma-\alpha) \\
& =(\gamma+\delta)-\gamma \\
& =\delta
\end{aligned}
$$

Além das estimações sobre o formato apresentado em 5.1, que sob as hipóteses 1,2 e 3 geram estimadores de diferença-em-diferença não viesados, também incluiremos outras variáveis de controle que podem fazer com que a hipótese mais forte (3) torne-se mais provável de ser efetiva e serão apresentados conjuntamente os dois resultados para todas as políticas, tanto para avaliar os efeitos sobre os crimes patrimoniais quanto sobre homicídios dolosos. 


\subsection{Disque Denúncia}

\begin{tabular}{|c|c|c|c|c|c|c|c|c|}
\hline \multicolumn{9}{|c|}{ TABELA 8} \\
\hline \multicolumn{9}{|c|}{ Resumo de resultados Diferença em diferença para o Disque Denúncia } \\
\hline & \multicolumn{4}{|c|}{ crime patrimonial } & & \multicolumn{3}{|c|}{ homicídio doloso } \\
\hline crime patrimonial & & Coef & & Coef & & Coef & & Coef \\
\hline emprego total & * & 7,813 & & & * & $-0,160$ & & \\
\hline densidade & * & 0,044 & & & * & 0,003 & & \\
\hline população & * & 0,000 & & & & 0,000 & & \\
\hline urbanização & * & 22,053 & & & * & $-0,098$ & & \\
\hline disque denuncia & & $-183,310$ & * & 749,509 & * & 29,590 & * & 37,603 \\
\hline dummy ano & * & 511,589 & * & 622,966 & * & 1,695 & & 1,208 \\
\hline dummy ano*disque denuncia & & 242,598 & & 173,535 & * & $-16,636$ & * & $-14,833$ \\
\hline constante & * & $-688,746$ & & $1.159,741$ & * & 27,067 & * & 17,647 \\
\hline
\end{tabular}

Na tabela 8 há a explicitação para os resultados das estimações de diferença-em-diferença para a implementação do sistema de Disque Denúncia, tanto para redução de crimes patrimoniais quanto para redução de homicídios dolosos (com e sem a utilização de outras variáveis de controle). Os resultados para as demais políticas serão apresentados desta mesma forma, com a explicitação das tabelas individuais com os resultados completos (com desvio-padrão dos coeficientes, teste $t$ e $p$-value) das estimações apresentadas no Apêndice dois deste trabalho.

Os coeficientes estatisticamente significantes a $10 \%$ estão destacados pela presença de asterisco ao lado dos coeficientes estimados. Além disto, serão apresentados no apêndice dois os resultados das mesmas estimações feitas com as variáveis dependentes em forma logarítmica, o que dá uma idéia de redução em termos percentuais dos crimes patrimoniais e dos homicídios dolosos após o tratamento de cada política de segurança pública.

Os resultados apresentados na tabela oito que chamam atenção em termos de coerência de sinais e de significância de coeficientes são: o sistema de Disque Denúncia foi de fato eficaz para redução de homicídios dolosos (com resultados coerentes tanto na estimação sem outras variáveis de controle quanto na estimação com variáveis de controle), a dummy de ano foi significante nas duas estimações para crimes patrimoniais, o que mostra que mesmo controlado por outros fatores (emprego, urbanização, população, etc.) houve uma tendência a crescimento deste gênero de crime durante o período 1997-2003. Além disto, há evidências de que a média amostral de homicídios dolosos dos municípios tratados por Disque Denúncia é superior á média 
amostral dos municípios do grupo de controle, mesmo controlado pelas demais variáveis de controle. Esta mesma constatação não é válida para o caso de crimes contra o patrimônio, onde não há evidência estatística de diferença das médias amostrais entre os dois grupos (tratados e controle).

Intuitivamente é de se imaginar que tanto crimes contra o patrimônio quanto homicídios sejam objetos de denúncias. O Disque Denúncia parece, à primeira vista, ser um instrumento plural de combate à violência. Os resultados obtidos evidenciam, entretanto, que há uma maior eficácia do instrumento de Disque Denúncia para redução de homicídios dolosos do que para queda de crimes patrimoniais. Isto se justificaria por uma propensão heterogênea entre os indivíduos delatarem um crime contra vida de outra pessoa (maior propensão) e delatarem crimes patrimoniais (menor propensão).

\subsection{Guarda Municipal}

\section{TABELA 9}

\begin{tabular}{|c|c|c|c|c|c|c|c|c|}
\hline \multicolumn{9}{|c|}{ Resumo de resultados Diferença em diferença para Guarda Municipal } \\
\hline & \multicolumn{4}{|c|}{ crime patrimonial } & & \multicolumn{3}{|c|}{ homicídio doloso } \\
\hline crime patrimonial & & Coef & & Coef & & Coef & & Coef \\
\hline emprego total & * & 8,062 & & & * & $-0,215$ & & \\
\hline densidade & * & 0,064 & & & * & 0,002 & & \\
\hline população & * & 0,000 & & & & 0,000 & & \\
\hline urbanização & * & 22,438 & & & * & $-0,117$ & & \\
\hline guarda municipal & * & $-283,625$ & * & 546,495 & * & 21,969 & * & 24,848 \\
\hline dummy ano & * & 506,785 & * & 622,476 & * & 2,067 & & 1,330 \\
\hline dummy ano*guarda municipal & & 103,354 & & 48,820 & * & $-6,654$ & & $-5,515$ \\
\hline constante & * & $-714,351$ & * & $1.147,690$ & * & 28,896 & * & 16,633 \\
\hline
\end{tabular}

A evidência de eficácia da implantação da Guarda Municipal para redução de criminalidade é mais fraca do que os resultados obtidos para Disque Denuncia. Só há significância para o estimador de diferença-em-diferença para a regressão com outros controles e com variável dependente, homicídios dolosos. Mais uma vez há sinais de diferença entre a média amostral de grupo de tratados e de controle para homicídios dolosos, enquanto os resultados para crimes patrimoniais são contraditórios entre as estimações com e sem outras variáveis de estado. 
A comparação entre os coeficientes dos estimadores de diferença-em-diferença reportados nas tabelas oito e nove sinaliza que o sistema Disque Denúncia parece ser superior em termos de eficácia para a contenção de homicídios dolosos comparado á implantação de Guarda Municipal.

A implantação de Guardas Municipais nos municípios tem um caráter mais repressivo do que duas outras medidas preventivas analisadas neste trabalho (Disque Denúncia e Lei Seca). A montagem de uma estrutura particular de policiamento municipal, mesmo sem poder efetivo de polícia (restrito por lei às polícias civil e militar), é iminentemente de caráter repressivo e não ataca diretamente algum foco específico gerador de mais homicídios como o faz a Lei Seca, por exemplo, o que pode justificar a menor eficácia relativa desta medida para redução da criminalidade e de homicídios em especial.

\subsection{Lei Seca}

\begin{tabular}{|c|c|c|c|c|c|c|c|}
\hline \multicolumn{8}{|c|}{ TABELA 10} \\
\hline \multicolumn{8}{|c|}{ Resumo de resultados Diferença em diferença para Lei Seca } \\
\hline & \multicolumn{5}{|c|}{ crime patrimonial } & \multicolumn{2}{|c|}{ homicídio doloso } \\
\hline crime patrimonial & & Coef & & Coef & & Coef & Coef \\
\hline emprego total & * & 7,802 & & & * & $-0,165$ & \\
\hline densidade & * & 0,067 & & & * & 0,003 & \\
\hline população & * & 0,000 & & & * & 0,000 & \\
\hline urbanização & * & 22,290 & & & * & $-0,108$ & \\
\hline Lei Seca & * & $-446,270$ & * & 255,705 & * & 24,486 & 30,017 \\
\hline dummy ano & * & 511,602 & * & 624,765 & * & 1,773 & 1,236 \\
\hline dummy ano*Lei Seca & & 65,223 & & $-10,479$ & * & $-10,190$ & * $\quad-8,736$ \\
\hline constante & * & $-704,429$ & * & $1.165,152$ & * & 27,877 & * $\quad 17,483$ \\
\hline
\end{tabular}

A estimação dos efeitos da Lei Seca aponta para evidências de redução de homicídios dolosos nos municípios tratados. Pode-se interpretar este resultado como um indício de que esta medida é direcionada mais para o controle de homicídios por motivos fúteis do que para redução de crimes patrimoniais, por motivos já explorados anteriormente.

A significância estatística de todos os coeficientes relacionados á dummy ano mostra que de fato ao longo dos seis anos do período amostral (1997-2003) as condições gerais de criminalidade 
parecem ter se deteriorado para além dos fatores capturados pelas demais variáveis de estado (por fatores não diretamente observados).

Os próprios coeficientes associados ás variáveis de controle também chamam atenção e confirmam alguns resultados encontrados no capítulo quatro. Municípios com mais população e com maior densidade populacional estão sujeitos a maiores taxas de criminalidade (patrimonial e homicídios dolosos).

Enquanto mais emprego está associado a mais crime patrimonial, provavelmente pelo efeito de aumento do retorno das atividades criminosas com menor restrição de oferta de bens patrimoniais objetos de crimes, mais emprego está associado a menos homicídio doloso. Pessoas empregadas no setor formal, capturadas pela estatística de emprego total, provavelmente tem menos tempo ocioso e práticas cotidianas que restringem as oportunidades de ocorrência de homicídios dolosos, como ingestão de dose excessiva de álcool e freqüência em bares e festas, que são os ambientes e as circunstâncias mais propícias á ocorrência de homicídios dolosos.

A implementação de Lei Seca está muito mais associada à ocorrência de mais homicídios dolosos do que à ocorrência de mais crimes patrimoniais. Parece claro que esta política foi desenhada prioritariamente com objetivo de reduzir o número de mortes por motivos banais, que ocorrem, em grande proporção, por conta da presença do álcool, conforme já explicitado anteriormente com números de estudos brasileiros e internacionais. A significância dos estimadores de diferença-em-diferença associados à variável de homicídio doloso em ambos os modelos evidencia que esta é uma política eficaz no combate dos homicídios dolosos.

O importante aspecto da Lei Seca é que ao evitar homicídios por motivos fúteis há uma minimização das perdas de capital humano e redução dos gastos em saúde para tratamento de vítimas não fatais, além da redução dos custos de manutenção de criminosos em sistema prisional. A Lei Seca, portanto, é implantada como instrumento mais direcionado à redução de homicídios e tem sido de grande eficácia para redução deste gênero de crimes segundo as estimações sugerem. 


\subsection{Secretaria de Segurança Pública Municipal}

\begin{tabular}{|c|c|c|c|c|c|c|c|c|}
\hline \multicolumn{9}{|c|}{ TABELA 11} \\
\hline \multicolumn{9}{|c|}{ Resumo de resultados Diferença em diferença para SSP } \\
\hline & \multicolumn{5}{|c|}{ crime patrimonial } & \multicolumn{3}{|c|}{ homicídio doloso } \\
\hline crime patrimonial & & Coef & & Coef & & Coef & & Coef \\
\hline emprego total & * & 7,887 & & & * & $-0,154$ & & \\
\hline densidade & * & 0,043 & & & * & 0,003 & & \\
\hline população & * & 0,000 & & & & 0,000 & & \\
\hline urbanização & * & 22,205 & & & * & $-0,101$ & & \\
\hline SSP & & $-191,119$ & * & 586,980 & * & 24,506 & * & 30,369 \\
\hline dummy ano & * & 508,778 & * & 621,380 & * & 1,656 & & 1,182 \\
\hline dummy ano*SSP & & 261,780 & & 183,620 & * & $-11,066$ & & $-9,637$ \\
\hline constante & * & $-696,919$ & * & $1.160,657$ & * & 27,293 & * & 17,722 \\
\hline
\end{tabular}

Os resultados encontrados para Secretaria de Segurança Pública Municipal são muito semelhantes aos apresentados para Guarda Municipal. O próprio caráter mais repressivo de ambas pode explicar a semelhança e seus efeitos limitados para redução de criminalidade no médio prazo. Conforme veremos a seguir uma hipótese razoável é de que estas medidas repressivas tenham efetividade restrita ao curto prazo e que os criminosos se adaptem ás condições policias mais restritivas e criem novos mecanismos no médio prazo para continuarem a aferir resultados de seus crimes patrimoniais. Esta adaptação dos criminosos explicaria a ineficácia deste tipo de medida repressiva para o combate aos crimes patrimoniais no médio prazo.

Além disto, a implantação de Secretaria de Segurança Municipal é uma decisão mais burocrática e pode não se refletir em melhora efetiva dos sistemas de segurança do município. Assim, pode ser que a despeito de o município ter uma Secretaria de Segurança Municipal, isto não implique melhora efetiva de condições de segurança.

Para tentar capturar esta eficácia, no curto prazo, das medidas preventivas (Guarda Municipal e Secretaria de Segurança Pública Municipal) fizemos, alternativamente às estimações de diferença-em-diferença, estimações em cross section para o ano 2000, em que existe a observação de todas as variáveis explicativas apresentadas no capítulo quatro de forma simultânea. Além disto, em 2000, as duas políticas de segurança repressivas já haviam sido 
implantadas em alguns municípios paulistas (Secretaria de Segurança Pública e instalação de Guardas Municipais). Como não ficou clara a diferença das médias amostrais para os grupos de tratamento e de controle nas estimações apresentadas nas tabelas nove e onze, para Guarda Municipal e Secretaria de Segurança Pública, a inserção de dummy separando grupo tratado e controle deve refletir de fato o efeito das políticas no ano 2000, por não haver indícios de viés de seleção entre os grupos tratados e de controle.

A análise dos resultados apresentados nas duas tabelas abaixo para o ano 2000 mostra que a existência de Guarda Municipal leva, no curto prazo, a menor nível de crimes contra o patrimônio, mas não tem efeito sobre número de homicídios dolosos nos municípios que as implementaram.

A tabela doze traz as estimações para crimes contra o patrimônio e a tabela treze traz os resultados das estimações para homicídios dolosos.

\begin{tabular}{lcccc}
\multicolumn{5}{c}{ Tabela 12 } \\
\hline \hline Efeito de políticas de segurança - cross section de ano 2000 \\
\hline crime patrimonial & Coef. & Std. Err. & $\mathrm{t}$ & $\mathrm{P}>|\mathrm{t}|$ \\
\hline guarda municipal & $-469,306$ & 204,192 & $-2,300$ & 0,022 \\
ssp & $-125,572$ & 449,528 & $-0,280$ & 0,780 \\
iprs educação & 4,874 & 6,342 & 0,770 & 0,443 \\
iprs longeveidade & $-15,299$ & 6,479 & $-2,360$ & 0,019 \\
iprs renda & 43,734 & 4,937 & 8,860 & 0,000 \\
emprego total & $-6,976$ & 2,883 & $-2,420$ & 0,016 \\
despesa pessoal & $-7,715$ & 4,512 & $-1,710$ & 0,088 \\
população & 0,000 & 0,000 & 1,590 & 0,114 \\
despesa transporte & $-3,220$ & 1,297 & $-2,480$ & 0,014 \\
despesa habitação & $-1,601$ & 0,952 & $-1,680$ & 0,094 \\
despesa total & 0,629 & 0,170 & 3,690 & 0,000 \\
urbanização & 4,076 & 3,248 & 1,260 & 0,211 \\
densidade & 0,015 & 0,034 & 0,440 & 0,662 \\
constante & 610,515 & 449,771 & 1,360 & 0,176
\end{tabular}

\begin{tabular}{lcccc}
\multicolumn{5}{c}{ Tabela 13 } \\
\hline \hline \multicolumn{5}{c}{ Efeito de políticas de segurança - cross section de ano 2000} \\
\hline homicídio doloso & Coef. & Std. Err. & $\mathrm{t}$ & $\mathrm{P}>|\mathrm{t}|$ \\
\hline guarda municipal & 12,923 & 4,457 & 2,900 & 0,004 \\
ssp & 5,423 & 9,812 & 0,550 & 0,581 \\
iprs educação & $-0,747$ & 0,138 & $-5,400$ & 0,000 \\
iprs longeveidade & $-0,278$ & 0,141 & $-1,960$ & 0,051 \\
iprs renda & 0,759 & 0,108 & 7,040 & 0,000 \\
emprego total & $-0,197$ & 0,063 & $-3,120$ & 0,002 \\
despesa pessoal & 0,198 & 0,098 & 2,010 & 0,045 \\
população & 0,000 & 0,000 & 0,530 & 0,600 \\
despesa transporte & 0,035 & 0,028 & 1,240 & 0,216 \\
despesa habitação & $-0,025$ & 0,021 & $-1,210$ & 0,226 \\
despesa total & 0,004 & 0,004 & 0,980 & 0,328 \\
urbanização & 0,130 & 0,071 & 1,830 & 0,068 \\
densidade & 0,002 & 0,001 & 2,350 & 0,020 \\
constante & 9,368 & 9,817 & 0,950 & 0,341
\end{tabular}

A implantação de Secretaria de Segurança Pública, por motivos já discutidos, não representa necessariamente melhoria nas condições de segurança e se mostra ineficaz para contenção da criminalidade nos municípios.

Já a implementação de Guardas Municipais se mostrou efetiva no controle de crimes contra o patrimônio no curto prazo, mas não conteve os homicídios dolosos nestes municípios. Esta política parece inibir, ao menos no curto prazo, os criminosos em roubarem carros, casas, etc., 
por conta de um maior contingente policial aumentar a probabilidade de o criminoso ser preso. Como esta política não afeta alguns condicionantes passionais que justificam boa parte dos homicídios dolosos, como ingestão de bebidas alcoólicas e porte de arma de fogo, sua efetividade para contenção de homicídios é reduzida.

Outros resultados obtidos das cross-section para o ano 2000 chamam atenção por confirmarem alguns fatos estilizados da literatura, tais como: municípios com expectativa de vida maior estão associados a menor taxa de criminalidade, municípios com maior renda tem mais criminalidade, mas, controlado pela renda, municípios com mais empregos têm menor criminalidade. Estes dois sinais dão um sinal de que o problema não é a renda, mas a desigualdade ocasionada pela renda concentrada.

Nas duas cross section as variáveis de estado têm maior significância estatística dos estimadores na explicação para ocorrência de crimes patrimoniais do que na explicação para ocorrência de homicídios dolosos, provavelmente em virtude de condicionantes não diretamente observáveis serem mais presentes neste segundo caso. Assim, maiores despesas com pessoal, com transporte e com habitação estão associadas a menor taxa de crimes patrimoniais nos municípios, mostrando que a presença municipal como provedora de bem estar colabora para menor incidência de crimes patrimoniais nestes locais.

As duas outras medidas de segurança pública, Lei Seca e Disque Denúncia, só foram implementadas nos primeiros municípios após o ano 2000, quando não há a ocorrência simultânea para todas as variáveis explicativas. Para análise destas políticas, então, ficamos restritos aos resultados já apresentados dos estimadores de diferença-em-diferença.

Se há evidência, através da cross section estimada para o ano de 2000, de que a presença da Guarda Municipal é mais efetiva na redução de crimes contra o patrimônio no curto prazo, a análise dos resultados dos estimadores de diferença-em-diferença para os anos de 1997 e 2003 sinaliza que os efeitos das políticas repressivas não são relevantes no médio prazo. Já as políticas de Lei Seca (principalmente) e Disque Denúncia são políticas mais eficazes para redução de homicídios dolosos do que para a redução de crimes contra o patrimônio. 
Portanto, as políticas de Lei Seca e de Disque Denúncia se mostram muito eficazes para redução dos homicídios nos municípios que as adotaram, enquanto o efeito de políticas repressivas, como Guarda Municipal e Secretaria de Segurança Pública, são inócuas para o controle deste tipo de crime no médio prazo e têm um efeito temporário para controle de Crimes Patrimoniais.

Os dados apresentados na parte três do Apêndice, com estimações que tomam as variáveis dependentes em termos logarítmicos de forma a se obter uma idéia de redução em termos percentuais dos homicídios e dos crimes patrimoniais como efeitos das implantações das diferentes políticas de segurança, trazem os seguintes resultados a partir dos estimadores de diferença-em-diferença de cada uma das políticas:

1 - todos os estimadores de diferença-em-diferença têm coeficientes negativos, o que representa que as políticas concorrem para redução da criminalidade.

2 - o sistema de Disque Denúncia tem estimadores estatisticamente signicantes a 10\% associados ao estimador de diferença-em-diferença para homicídio doloso, tanto com a inserção de outros controles como na estimação sem outros controles. Os coeficientes sinalizam uma redução de $30 \%$ (sem as demais variáveis de controle) e de 39\% (para o modelo com as demais variáveis de controle) nos homicídios dolosos dos municípios tratados.

3 - Apesar de estatisticamente não significantes os testes $t$ mais altos para os estimadores de diferença-em-diferença associados à redução de crimes patrimoniais estão relacionados à implantação de Guarda Municipal, com coeficientes que sinalizam queda de 9\% (para o modelo com outros controles) e de 13\% (para o modelo sem outras variáveis de controle).

4 - Lei Seca, a 20\% de significância, tem estimadores estatisticamente relevantes para redução tanto de homicídios dolosos (da ordem de 30\%) quanto de crimes patrimoniais (próximo a 10\%). 


\section{Conclusão}

A criminalidade crescente nos municípios paulistas na segunda metade dos anos noventa levou municípios a tomarem medidas alternativas para o controle da violência em seu território. Apesar da segurança pública ser objeto de responsabilidade estadual e/ou federal, instrumentos preventivos e repressivos adicionais foram criados pelos municípios para suprir a insuficiência dos instrumentos estaduais e federais implementados até então.

O primeiro diagnóstico do trabalho é que o aumento da violência se concentra, via de regra, em municípios mais populosos, mais urbanizados, com maior nível de renda per capita e com maior densidade demográfica. Tudo isto caracteriza muito bem os grandes centros urbanos, onde a desigualdade social é crescente, com incapacidade de absorção de força de trabalho migrante e com criação de condições muito desiguais de moradia, emprego, transporte, entre outros aspectos.

Por outro lado, municípios com maior nível educacional e que gastam mais recursos em áreas que trazem benefícios sociais diretos (transporte, habitação, entre outros) têm, em média, menor taxa de criminalidade de equilíbrio.

A partir do diagnóstico do perfil dos municípios mais violentos e do mapeamento de quais municípios empreenderam políticas complementares de segurança foram feitas estimações empíricas para testar a eficácia destas políticas para a redução efetiva de dois gêneros de crimes: crimes patrimoniais e homicídios dolosos. Destaca-se o fato de os crimes patrimoniais terem muito mais influência das variáveis de estado, conforme preconizado pelos modelos teóricos apresentados neste trabalho, do que os homicídios dolosos, que fogem à racionalidade econômica estrita e têm outras componentes causadoras.

Os dois principais resultados a que se chegou foram:

1 - Políticas de segurança que potencialmente aumentam contingente policial e força repressiva nos municípios, como implantação de Guarda Municipal, fazem criminosos terem a percepção de 
que a probabilidade de serem pegos é maior, o que leva a menor nível de crimes contra o patrimônio (crimes mais sujeitos à racionalidade econômica) no curto prazo. Entretanto, no médio prazo não parece haver efeito destas políticas para controle dos crimes patrimoniais, com sinais de que os agentes conseguem se adaptar ás novas condições mais restritivas de policiamento e criam novos mecanismos para lidar com isto.

Fica claro que aspectos sócio-econômicos e demográficos têm efeito permanente para redução de criminalidade, principalmente relacionada aos crimes patrimôniais. Além disto, outras políticas, como a Lei Seca, desenhada originalmente para controlar homicídios, têm externalidades positivas para crimes patrimoniais, reduzindo a incidência destes crimes como efeito secundário.

2 - Políticas de segurança mais ligadas à prevenção, como aprovação de Lei Seca, estão mais vinculadas à redução de homicídios dolosos. Esta lei reduziu efetivamente o nível de homicídios dolosos ao inibir a ingestão de álcool, que leva a maior probabilidade de que crimes passionais, ou crimes por motivos fúteis, ocorram. A Lei Seca ataca diretamente um fator essencial que está por trás da ocorrência de homicídios, segundo estudos brasileiros e internacionais, e tem efetividade na redução deste malefício à sociedade, reduzindo as perdas de capital humano, os custos com tratamento das vítimas e os custos prisionais.

Além disto, o sistema de Disque Denúncia também parece ser mais efetivo para combater crimes de homicídio do que crimes patrimoniais, provavelmente por uma propensão heterogênea em denunciar crimes de homicídio (maior) e patrimoniais (menor).

Por fim, tanto as políticas repressivas de segurança de curto prazo, que agem sobre a probabilidade percebida pelos agentes de serem presos em ato ilícito, quanto medidas de médio prazo que aumentam a utilidade do indivíduo com melhores condições educacionais, de transporte e de educação, têm efeitos positivos para o controle da criminalidade. $\mathrm{O}$ ataque simultâneo destas questões é que dá condições à contenção da violência no curto prazo, com políticas diretas de segurança, e à formação de bases mais sólidas que restrinjam os incentivos à criminalidade futura com condições educacionais e de bem estar social melhores para o futuro. 


\section{Apêndice}

\section{I - Teste de Hausman para Comparação de Modelos de Efeito Fixo e Efeito Aleatório}

A opção final por um ou outro modelo está vinculada às propriedades que os estimadores das duas formulações apresentam e da hipótese que se tem acerca da relação entre o termos não observável $\left(\mathrm{a}_{\mathrm{i}}\right)$ e o vetor de variáveis explicativa $\left(\mathrm{X}_{\mathrm{it}}\right)$. Neste sentido, os autores, de forma geral, arbitram por um ou outro modelo a partir da análise se $a_{i}$ é mais bem visto como um parâmetro a ser estimado, ou é um resultado aleatório. Normalmente quando se trabalha com municípios ou estados, segundo Wooldridge, opta-se pela estimação por efeito fixo, por haver características sócio-demográficas não observáveis dos municípios que são fixas no tempo e estão correlacionadas com as variáveis explicativas. O trade-off entre a escolha de um ou outro modelo está no fato de que, se $a_{i}$ for de fato correlacionada com $X_{i t}$ a estimação por efeito fixo gerará estimadores inconsistentes (não converge assintoticamente para valor real dos coeficientes). Por outro lado, se $\mathrm{a}_{\mathrm{i}}$ não for correlacionada com $\mathrm{X}_{\mathrm{it}}$, então o estimador por efeito aleatório além de consistente será o mais eficiente (menor variância).

Para se fazer a opção entre os modelos pode-se aplicar o teste desenvolvido por Hausman (1978) que testa se os coeficientes gerados pelos dois modelos são estatisticamente diferentes. A formulação deste teste é feita de tal sorte que se testará um estimador que sob qualquer hipótese é consistente contra um estimador que é eficiente e consistente sob a hipótese que está sendo testada e não é consistente caso contrário.

No caso do teste entre os modelos de efeito fixo estima-se o modelo de efeito fixo que é sempre consistente e depois é estimado o modelo de efeito aleatório que é consistente e eficiente sob $\mathrm{H}_{0}$. Feitas as duas estimações comparam-se os coeficientes e testa-se se estes conjuntos de coeficientes são ou não estatisticamente diferentes.

O teste de Hausman traz a comparação entre o modelo de efeito fixo - consistente sob $\mathrm{H}_{\mathrm{o}}$ e sob $\mathrm{H}_{\mathrm{a}}$ - e o modelo com as mesmas variáveis de efeito aleatório - consistente e eficiente sob $\mathrm{H}_{0}$. 
A não rejeição de $\mathrm{H}_{\mathrm{o}}$ leva a escolha do modelo que é não apenas consistente, mas também eficiente sob $\mathrm{H}_{\mathrm{o}}$ (efeito aleatório neste caso), enquanto a rejeição de $\mathrm{H}_{\mathrm{o}}$ leva a opção pelo modelo consistente sob $\mathrm{H}_{\mathrm{a}}$ (efeito fixo neste caso). De forma mais geral, o teste de Hausman é executado para testar se o efeito aleatório é ortogonal ou não em relação ao vetor de regressores. Caso seja, tanto OLS quanto GLS são estimadores consistentes, mas OLS é ineficiente. Por outro lado se não for validada hipótese de ortogonalidade, OLS permanece consistente, enquanto GLS se torna inconsistente.

Sob esta hipótese a forma mais eficiente de estimação é a estimação por efeito aleatório. 


\section{II - Estimações de diferença-em-diferença com variáveis dependentes em nível.}

\section{Disque Denúncia}

Tabela 14

\begin{tabular}{lcccc}
\hline \multicolumn{5}{c}{ Tabela 14 } \\
\hline \hline crime patrimonial & Coeficiente & Std. Error & $\mathbf{t}$ & $\mathbf{P}>|\mathbf{t}|$ \\
\hline EMPREGO & 7.813 & 1.836 & 4.255 & 0.000 \\
DENSIDADE & 0.044 & 0.023 & 1.883 & 0.060 \\
POPULACAO & 0.000 & 0.000 & 3.583 & 0.000 \\
URBANIZACAO & 22.053 & 1.544 & 14.284 & 0.000 \\
DISQUE DENÚNCIA & -183.310 & 308.011 & -0.595 & 0.552 \\
ANO & 511.589 & 45.955 & 11.132 & 0.000 \\
ANO*DISQUE DENÚNCIA & 242.598 & 407.732 & 0.595 & 0.552 \\
CONSTANTE & -688.746 & 122.755 & -5.611 & 0.000
\end{tabular}

Tabela 16

\begin{tabular}{lcccc}
\hline \hline \multicolumn{4}{c}{ Estimador de diferença-em-diferença para Disque Denúncia } \\
\hline \hline homicídio doloso & Coeficiente & Std. Error & $\mathbf{t}$ & $\mathbf{P}>\mathbf{| t |}$ \\
\hline EMPREGO & -0.160 & 0.054 & -2.949 & 0.003 \\
DENSIDADE & 0.003 & 0.000 & 8.026 & 0.000 \\
POPULACAO & 0.000 & 0.000 & -0.664 & 0.507 \\
URBANIZACAO & -0.098 & 0.035 & -2.801 & 0.005 \\
DISQUE DENÚNCIA & 29.590 & 5.218 & 5.671 & 0.000 \\
ANO & 1.695 & 1.021 & 1.660 & 0.097 \\
ANO*DISQUE DENÚNCIA & -16.636 & 6.919 & -2.404 & 0.016 \\
CONSTANTE & 27.067 & 2.885 & 9.381 & 0.000
\end{tabular}

\section{Guarda Municipal}

Tabela 18

\begin{tabular}{lcccc}
\hline \hline \multicolumn{4}{c}{ Estimador de diferença-em-diferença para Guarda Municipal } \\
\hline \hline crime patrimonial & Coeficiente & Std. Error & $\mathbf{t}$ & $\mathbf{P > | \mathbf { t }}$ \\
\hline EMPREGO & 8.062 & 1.843 & 4.376 & 0.000 \\
DENSIDADE & 0.064 & 0.026 & 2.410 & 0.016 \\
POPULACAO & 0.000 & 0.000 & 3.844 & 0.000 \\
URBANIZACAO & 22.438 & 1.558 & 14.400 & 0.000 \\
Guarda Municipal & -283.625 & 178.421 & -1.590 & 0.112 \\
ANO & 506.785 & 46.946 & 10.795 & 0.000 \\
ANO*Guarda Municipal & 103.354 & 225.964 & 0.457 & 0.648 \\
CONSTANTE & -714.351 & 123.693 & -5.775 & 0.000
\end{tabular}

Tabela 20

\begin{tabular}{lcccc}
\hline \hline \multicolumn{4}{c}{ Estimador de diferença-em-diferença para Guarda Municipal } \\
\hline \hline homicídio doloso & Coeficiente & Std. Error & $\mathbf{t}$ & $\mathbf{P}>|\mathbf{t}|$ \\
\hline EMPREGO & -0.215 & 0.053 & -4.044 & 0.000 \\
DENSIDADE & 0.002 & 0.000 & 4.691 & 0.000 \\
POPULACAO & 0.000 & 0.000 & 0.440 & 0.660 \\
URBANIZACAO & -0.117 & 0.034 & -3.403 & 0.001 \\
Guarda Municipal & 21.969 & 2.983 & 7.364 & 0.000 \\
ANO & 2.067 & 1.028 & 2.011 & 0.045 \\
ANO*Guarda Municipal & -6.654 & 3.794 & -1.754 & 0.080 \\
CONSTANTE & 28.896 & 2.840 & 10.175 & 0.000
\end{tabular}

Tabela 15

\begin{tabular}{lrrrr}
\hline \hline \multicolumn{5}{c}{ Estimador de diferença-em-diferença para Disque Denúncia } \\
\hline \hline crime patrimonial & Coeficiente & Std. Error & \multicolumn{1}{c}{ t } & P>|t| \\
\hline DISQUE DENÚNCIA & 749.509 & 320.337 & 2.340 & 0.019 \\
ANO & 622.966 & 50.453 & 12.347 & 0.000 \\
ANO*DISQUE DENÚNCIA & 173.535 & 453.025 & 0.383 & 0.702 \\
CONSTANTE & $1,159.741$ & 35.676 & 32.508 & 0.000
\end{tabular}

Tabela 17

\begin{tabular}{lcccc}
\hline \hline \multicolumn{4}{c}{ Estimador de diferença-em-diferença para Disque Denúncia } \\
\hline \hline homicídio doloso & Coeficiente & Std. Error & $\mathbf{t}$ & $\mathbf{P}>|\mathbf{t}|$ \\
\hline DISQUE DENÚNCIA & 37.603 & 5.116 & 7.351 & 0.000 \\
ANO & 1.208 & 1.059 & 1.140 & 0.255 \\
ANO*DISQUE DENÚNCIA & -14.833 & 7.233 & -2.051 & 0.041 \\
CONSTANTE & 17.647 & 0.757 & 23.301 & 0.000
\end{tabular}

Tabela 19

\begin{tabular}{lrrrl}
\hline \hline \multicolumn{4}{c}{ Estimador de diferença-em-diferença para Guarda Municipal } \\
\hline \hline crime patrimonial & Coeficiente & Std. Error & \multicolumn{1}{c}{$\mathbf{t}$} & $\mathbf{P}>|\mathbf{t}|$ \\
\hline Guarda Municipal & 546.495 & 177.182 & 3.084 & 0.002 \\
ANO & 622.476 & 51.467 & 12.095 & 0.000 \\
ANO*Guarda Municipal & 48.820 & 250.573 & 0.195 & 0.846 \\
CONSTANTE & $1,147.690$ & 36.392 & 31.537 & 0.000
\end{tabular}

Tabela 21

\begin{tabular}{lcccc}
\hline \hline \multicolumn{4}{c}{ Estimador de diferença-em-diferença para Guarda Municipal } \\
\hline \hline homicídio doloso & Coeficiente & Std. Error & $\mathbf{t}$ & $\mathbf{P}>\mathbf{| t} \mid$ \\
\hline Guarda Municipal & 24.848 & 2.769 & 8.974 & 0.000 \\
ANO & 1.330 & 1.053 & 1.263 & 0.207 \\
ANO*Guarda Municipal & -5.515 & 3.913 & -1.410 & 0.159 \\
CONSTANTE & 16.633 & 0.753 & 22.086 & 0.000
\end{tabular}




\section{Lei Seca}

Tabela 22

\begin{tabular}{lcccc}
\hline \hline \multicolumn{5}{c}{ Estimador de diferença-em-diferença para Lei Seca } \\
\hline \hline crime patrimonial & Coeficiente & Std. Error & $\mathbf{t}$ & $\mathbf{P}>|\mathbf{t}|$ \\
\hline EMPREGO & 7.802 & 1.832 & 4.260 & 0.000 \\
DENSIDADE & 0.067 & 0.025 & 2.714 & 0.007 \\
POPULACAO & 0.000 & 0.000 & 3.404 & 0.001 \\
URBANIZACAO & 22.290 & 1.545 & 14.429 & 0.000 \\
Lei Seca & -446.270 & 229.906 & -1.941 & 0.053 \\
ANO & 511.602 & 46.079 & 11.103 & 0.000 \\
ANO*Lei Seca & 65.223 & 309.361 & 0.211 & 0.833 \\
CONSTANTE & -704.429 & 122.671 & -5.742 & 0.000
\end{tabular}

Tabela 24

\begin{tabular}{lcccc}
\hline \hline \multicolumn{5}{c}{ Estimador de diferença-em-diferença para Lei Seca } \\
\hline \hline homicídio doloso & Coeficiente & Std. Error & $\mathbf{t}$ & $\mathbf{P}>|\mathbf{t}|$ \\
\hline EMPREGO & -0.165 & 0.054 & -3.068 & 0.002 \\
DENSIDADE & 0.003 & 0.000 & 6.228 & 0.000 \\
POPULACAO & 0.000 & 0.000 & 1.951 & 0.051 \\
URBANIZACAO & -0.108 & 0.035 & -3.107 & 0.002 \\
Lei Seca & 24.486 & 3.885 & 6.302 & 0.000 \\
ANO & 1.773 & 1.028 & 1.724 & 0.085 \\
ANO*Lei Seca & -10.190 & 5.243 & -1.944 & 0.052 \\
CONSTANTE & 27.877 & 2.872 & 9.707 & 0.000
\end{tabular}

Secretaria de Segurança Pública Municipal

Tabela 26

\begin{tabular}{lcccc}
\hline \hline \multicolumn{5}{c}{ Estimador de diferença-em-diferença para SSP } \\
\hline \hline crime patrimonial & Coeficiente & Std. Error & $\mathbf{t}$ & $\mathbf{P}>|\mathbf{t}|$ \\
\hline EMPREGO & 7.887 & 1.842 & 4.281 & 0.000 \\
DENSIDADE & 0.043 & 0.023 & 1.851 & 0.064 \\
POPULACAO & 0.000 & 0.000 & 3.626 & 0.000 \\
URBANIZACAO & 22.205 & 1.553 & 14.296 & 0.000 \\
SSP & -191.119 & 259.321 & -0.737 & 0.461 \\
ANO & 508.778 & 46.367 & 10.973 & 0.000 \\
ANO*SSP & 261.780 & 349.456 & 0.749 & 0.454 \\
CONSTANTE & -696.919 & 123.344 & -5.650 & 0.000
\end{tabular}

Tabela 28

\begin{tabular}{lcccc}
\hline \hline \multicolumn{5}{c}{ Estimador de diferença-em-diferença para SSP } \\
\hline \hline homicídio doloso & Coeficiente & Std. Error & $\mathbf{t}$ & $\mathbf{P}>|\mathbf{t}|$ \\
\hline EMPREGO & -0.154 & 0.054 & -2.839 & 0.005 \\
DENSIDADE & 0.003 & 0.000 & 8.204 & 0.000 \\
POPULACAO & 0.000 & 0.000 & -0.514 & 0.608 \\
URBANIZACAO & -0.101 & 0.035 & -2.891 & 0.004 \\
SSP & 24.506 & 4.386 & 5.588 & 0.000 \\
ANO & 1.656 & 1.032 & 1.606 & 0.109 \\
ANO*SSP & -11.066 & 5.923 & -1.868 & 0.062 \\
CONSTANTE & 27.293 & 2.890 & 9.443 & 0.000
\end{tabular}

Tabela 23

\begin{tabular}{lcccc}
\hline \hline \multicolumn{5}{c}{ Estimador de diferença-em-diferença para Lei Seca } \\
\hline \hline crime patrimonial & Coeficiente & Std. Error & $\mathbf{t}$ & $\mathbf{P}>|\mathbf{t}|$ \\
\hline Lei Seca & 255.705 & 245.265 & 1.043 & 0.297 \\
ANO & 624.765 & 51.301 & 12.178 & 0.000 \\
ANO*Lei Seca & -10.479 & 346.858 & -0.030 & 0.976 \\
CONSTANTE & 1165.152 & 36.275 & 32.120 & 0.000
\end{tabular}

Tabela 25

\begin{tabular}{lcccc}
\hline \hline \multicolumn{5}{c}{ Estimador de diferença-em-diferença para Lei Seca } \\
\hline \hline homicídio doloso & Coeficiente & Std. Error & $\mathbf{t}$ & $\mathbf{P}>|\mathbf{t}|$ \\
\hline Lei Seca & 30.017 & 3.860 & 7.777 & 0.000 \\
ANO & 1.236 & 1.064 & 1.161 & 0.246 \\
ANO*Lei Seca & -8.736 & 5.456 & -1.601 & 0.110 \\
CONSTANTE & 17.483 & 0.761 & 22.969 & 0.000
\end{tabular}

Tabela 27

\begin{tabular}{lcccc}
\hline \hline \multicolumn{5}{c}{ Estimador de diferença-em-diferença para SSP } \\
\hline \hline crime patrimonial & Coeficiente & Std. Error & $\mathbf{t}$ & $\mathbf{P}>|\mathbf{t}|$ \\
\hline SSP & 586.980 & 274.927 & 2.135 & 0.033 \\
ANO & 621.380 & 50.973 & 12.190 & 0.000 \\
ANO*SSP & 183.620 & 388.806 & 0.472 & 0.637 \\
CONSTANTE & 1160.657 & 36.043 & 32.202 & 0.000
\end{tabular}

Tabela 29

\begin{tabular}{lcccc}
\hline \hline \multicolumn{5}{c}{ Estimador de diferença-em-diferença para SSP } \\
\hline \hline homicídio doloso & Coeficiente & Std. Error & $\mathbf{t}$ & $\mathbf{P}>|\mathbf{t}|$ \\
\hline SSP & 30.369 & 4.391 & 6.916 & 0.000 \\
ANO & 1.182 & 1.074 & 1.101 & 0.271 \\
ANO*SSP & -9.637 & 6.208 & -1.552 & 0.121 \\
CONSTANTE & 17.722 & 0.768 & 23.087 & 0.000
\end{tabular}




\section{III - Estimações de diferença-em-diferença com variáveis dependentes em logaritmo}

\section{natural.}

\section{Disque Denúncia}

\begin{tabular}{lcccc}
\multicolumn{5}{c}{ Tabela 30 } \\
\hline \hline \multicolumn{4}{c}{ Estimador de diferença-em-diferença para Disque Denúncia } \\
\hline \hline log(crime patrimonial) & Coeficiente & Std. Error & $\mathbf{t}$ & $\mathbf{P}>\mathbf{| t} \mid$ \\
\hline EMPREGO & 0.006 & 0.002 & 2.930 & 0.004 \\
DENSIDADE & 0.000 & 0.000 & 3.297 & 0.001 \\
POPULACAO & 0.000 & 0.000 & 2.380 & 0.017 \\
URBANIZACAO & 0.016 & 0.001 & 12.778 & 0.000 \\
DISQUE DENÚNCIA & 0.076 & 0.132 & 0.579 & 0.563 \\
ANO & 0.382 & 0.033 & 11.442 & 0.000 \\
ANO*DISQUE DENÚNCIA & -0.083 & 0.197 & -0.424 & 0.672 \\
CONSTANTE & 5.481 & 0.104 & 52.594 & 0.000 \\
& & & & \\
\multicolumn{1}{c}{ Estimador de diferença-em-diferença para Disque Denúncia } \\
\hline \hline log(homicídio doloso) & Coeficiente & Std. Error & $\mathbf{t}$ & $\mathbf{P}>|\mathbf{t}|$ \\
\hline EMPREGO & -0.008 & 0.004 & -2.130 & 0.034 \\
DENSIDADE & 0.000 & 0.000 & 5.650 & 0.000 \\
POPULACAO & 0.000 & 0.000 & -0.165 & 0.869 \\
URBANIZACAO & -0.006 & 0.002 & -3.057 & 0.002 \\
DISQUE DENÚNCIA & 0.998 & 0.162 & 6.152 & 0.000 \\
ANO & 0.089 & 0.056 & 1.580 & 0.115 \\
ANO*DISQUE DENÚNCIA & -0.394 & 0.227 & -1.740 & 0.082 \\
CONSTANTE & 3.159 & 0.156 & 20.317 & 0.000
\end{tabular}

\begin{tabular}{lcccc}
\multicolumn{5}{c}{ Tabela 31 } \\
\hline \hline \multicolumn{4}{c}{ Estimador de diferença-em-diferença para Disque Denúncia } \\
\hline \hline log(crime patrimonial) & Coeficiente & Std. Error & $\mathbf{t}$ & $\mathbf{P}>|\mathbf{t}|$ \\
\hline DISQUE DENÚNCIA & 0.669 & 0.087 & 7.722 & 0.000 \\
ANO & 0.461 & 0.037 & 12.585 & 0.000 \\
ANO*DISQUE DENÚNCIA & -0.138 & 0.145 & -0.954 & 0.340 \\
CONSTANTE & 6.857 & 0.027 & 249.663 & 0.000
\end{tabular}

\section{Guarda Municipal}

Tabela 34

\begin{tabular}{lcccc}
\hline \hline \multicolumn{4}{c}{ Estimador de diferença-em-diferença para Guarda Municipal } \\
\hline \hline crime patrimonial & Coeficiente & Std. Error & $\mathbf{t}$ & $\mathbf{P}>|\mathbf{t}|$ \\
\hline EMPREGO & 0.006 & 0.002 & 2.932 & 0.003 \\
DENSIDADE & 0.000 & 0.000 & 3.323 & 0.001 \\
POPULACAO & 0.000 & 0.000 & 2.524 & 0.012 \\
URBANIZACAO & 0.016 & 0.001 & 12.692 & 0.000 \\
Guarda Municipal & 0.004 & 0.076 & 0.054 & 0.957 \\
ANO & 0.384 & 0.035 & 11.082 & 0.000 \\
ANO*Guarda Municipal & -0.086 & 0.094 & -0.916 & 0.360 \\
CONSTANTE & 5.476 & 0.105 & 52.026 & 0.000
\end{tabular}

Tabela 36

\begin{tabular}{lcccc}
\hline \hline \multicolumn{4}{c}{ Estimador de diferença-em-diferença para Guarda Municipal } \\
\hline \hline homicídio doloso & Coeficiente & Std. Error & $\mathbf{t}$ & $\mathbf{P}>|\mathbf{t}|$ \\
\hline EMPREGO & -0.010 & 0.003 & -3.313 & 0.001 \\
DENSIDADE & 0.000 & 0.000 & 3.109 & 0.002 \\
POPULACAO & 0.000 & 0.000 & 1.010 & 0.313 \\
URBANIZACAO & -0.007 & 0.002 & -3.519 & 0.001 \\
Guarda Municipal & 0.917 & 0.147 & 6.222 & 0.000 \\
ANO & 0.103 & 0.057 & 1.815 & 0.070 \\
ANO*Guarda Municipal & -0.154 & 0.177 & -0.867 & 0.386 \\
CONSTANTE & 3.244 & 0.155 & 20.924 & 0.000
\end{tabular}

Tabela 35

\begin{tabular}{lcccc}
\hline \hline \multicolumn{4}{c}{ Estimador de diferença-em-diferença para Guarda Municipal } \\
\hline \hline crime patrimonial & Coeficiente & Std. Error & $\mathbf{t}$ & $\mathbf{P}>|\mathbf{t}|$ \\
\hline Guarda Municipal & 0.543 & 0.066 & 8.260 & 0.000 \\
ANO & 0.464 & 0.038 & 12.308 & 0.000 \\
ANO*Guarda Municipal & -0.129 & 0.091 & -1.421 & 0.155 \\
CONSTANTE & 6.843 & 0.028 & 242.291 & 0.000
\end{tabular}

Tabela 37

\begin{tabular}{lcccc}
\hline \hline \multicolumn{4}{c}{ Estimador de diferença-em-diferença para Guarda Municipal } \\
\hline \hline homicídio doloso & Coeficiente & Std. Error & $\mathbf{t}$ & $\mathbf{P}>|\mathbf{t}|$ \\
\hline Guarda Municipal & 1.004 & 0.130 & 7.703 & 0.000 \\
ANO & 0.065 & 0.058 & 1.128 & 0.260 \\
ANO*Guarda Municipal & -0.101 & 0.167 & -0.608 & 0.544 \\
CONSTANTE & 2.554 & 0.041 & 62.101 & 0.000
\end{tabular}




\section{Lei Seca}

Tabela 38

\begin{tabular}{lcccc}
\hline \hline \multicolumn{4}{c}{ Estimador de diferença-em-diferença para Lei Seca } \\
\hline \hline crime patrimonial & Coeficiente & Std. Error & $\mathbf{t}$ & $\mathbf{P}>|\mathbf{t}|$ \\
\hline EMPREGO & 0.006 & 0.002 & 2.930 & 0.004 \\
DENSIDADE & 0.000 & 0.000 & 3.864 & 0.000 \\
POPULACAO & 0.000 & 0.000 & 2.393 & 0.017 \\
URBANIZACAO & 0.016 & 0.001 & 12.766 & 0.000 \\
Lei Seca & -0.089 & 0.062 & -1.436 & 0.151 \\
ANO & 0.382 & 0.034 & 11.310 & 0.000 \\
ANO*Lei Seca & -0.046 & 0.098 & -0.473 & 0.637 \\
CONSTANTE & 5.477 & 0.105 & 52.387 & 0.000
\end{tabular}

Tabela 40

\begin{tabular}{lcccc}
\hline \hline \multicolumn{5}{c}{ Estimador de diferença-em-diferença para Lei Seca } \\
\hline \hline homicídio doloso & Coeficiente & Std. Error & $\mathbf{t}$ & $\mathbf{P}>|\mathbf{t}|$ \\
\hline EMPREGO & -0.008 & 0.003 & -2.313 & 0.021 \\
DENSIDADE & 0.000 & 0.000 & 4.906 & 0.000 \\
POPULACAO & 0.000 & 0.000 & 2.558 & 0.011 \\
URBANIZACAO & -0.006 & 0.002 & -3.242 & 0.001 \\
Lei Seca & 0.893 & 0.173 & 5.176 & 0.000 \\
ANO & 0.092 & 0.056 & 1.630 & 0.104 \\
ANO*Lei Seca & -0.301 & 0.226 & -1.333 & 0.183 \\
CONSTANTE & 3.181 & 0.156 & 20.446 & 0.000
\end{tabular}

\section{Secretaria de Segurança Pública Municipal}

Tabela 42

\begin{tabular}{lcccc}
\hline \hline \multicolumn{5}{c}{ Estimador de diferença-em-diferença para SSP } \\
\hline \hline crime patrimonial & Coeficiente & Std. Error & $\mathbf{t}$ & $\mathbf{P}>|\mathbf{t}|$ \\
\hline EMPREGO & 0.006 & 0.002 & 2.933 & 0.003 \\
DENSIDADE & 0.000 & 0.000 & 3.244 & 0.001 \\
POPULACAO & 0.000 & 0.000 & 2.363 & 0.018 \\
URBANIZACAO & 0.016 & 0.001 & 12.726 & 0.000 \\
SSP & 0.078 & 0.110 & 0.708 & 0.479 \\
ANO & 0.381 & 0.034 & 11.268 & 0.000 \\
ANO*SSP & -0.035 & 0.156 & -0.227 & 0.821 \\
CONSTANTE & 5.480 & 0.105 & 52.395 & 0.000
\end{tabular}

Tabela 44

\begin{tabular}{lcccc}
\hline \hline \multicolumn{5}{c}{ Estimador de diferença-em-diferença para SSP } \\
\hline \hline homicídio doloso & Coeficiente & Std. Error & $\mathbf{t}$ & $\mathbf{P}>|\mathbf{t}|$ \\
\hline EMPREGO & -0.007 & 0.004 & -2.097 & 0.036 \\
DENSIDADE & 0.000 & 0.000 & 5.688 & 0.000 \\
POPULACAO & 0.000 & 0.000 & 0.006 & 0.996 \\
URBANIZACAO & -0.006 & 0.002 & -3.075 & 0.002 \\
SSP & 0.860 & 0.206 & 4.178 & 0.000 \\
ANO & 0.086 & 0.056 & 1.530 & 0.127 \\
ANO*SSP & -0.269 & 0.270 & -0.997 & 0.319 \\
CONSTANTE & 3.159 & 0.156 & 20.292 & 0.000
\end{tabular}

Tabela 39

\begin{tabular}{lcccc}
\hline \hline \multicolumn{5}{c}{ Estimador de diferença-em-diferença para Lei Seca } \\
\hline \hline crime patrimonial & Coeficiente & Std. Error & $\mathbf{t}$ & $\mathbf{P}>|\mathbf{t}|$ \\
\hline Lei Seca & 0.387 & 0.054 & 7.106 & 0.000 \\
ANO & 0.461 & 0.037 & 12.330 & 0.000 \\
ANO*Lei Seca & -0.106 & 0.080 & -1.323 & 0.186 \\
CONSTANTE & 6.857 & 0.028 & 244.810 & 0.000
\end{tabular}

Tabela 41

\begin{tabular}{lcccc}
\hline \hline \multicolumn{5}{c}{ Estimador de diferença-em-diferença para Lei Seca } \\
\hline \hline homicídio doloso & Coeficiente & Std. Error & $\mathbf{t}$ & $\mathbf{P}>|\mathbf{t}|$ \\
\hline Lei Seca & 1.121 & 0.169 & 6.625 & 0.000 \\
ANO & 0.063 & 0.057 & 1.102 & 0.271 \\
ANO*Lei Seca & -0.230 & 0.245 & -0.937 & 0.349 \\
CONSTANTE & 2.590 & 0.041 & 62.990 & 0.000
\end{tabular}

Tabela 43

\begin{tabular}{lcccc}
\hline \hline \multicolumn{5}{c}{ Estimador de diferença-em-diferença para SSP } \\
\hline \hline crime patrimonial & Coeficiente & Std. Error & $\mathbf{t}$ & $\mathbf{P}>|\mathbf{t}|$ \\
\hline SSP & 0.576 & 0.082 & 7.050 & 0.000 \\
ANO & 0.460 & 0.037 & 12.414 & 0.000 \\
ANO*SSP & -0.095 & 0.124 & -0.763 & 0.445 \\
CONSTANTE & 6.856 & 0.028 & 246.701 & 0.000
\end{tabular}

Tabela 45

\begin{tabular}{lcccc}
\hline \hline \multicolumn{5}{c}{ Estimador de diferença-em-diferença para SSP } \\
\hline \hline homicídio doloso & Coeficiente & Std. Error & $\mathbf{t}$ & $\mathbf{P}>|\mathbf{t}|$ \\
\hline SSP & 1.121 & 0.192 & 5.849 & 0.000 \\
ANO & 0.060 & 0.058 & 1.045 & 0.297 \\
ANO*SSP & -0.199 & 0.251 & -0.794 & 0.427 \\
CONSTANTE & 2.600 & 0.041 & 63.058 & 0.000
\end{tabular}




\section{Referências Bibliográficas}

Andreoni, J. "Reasonable Doubt and the Optimal Magnitude of Fines: Should the Penalty Fit the Crime?" RAND Journal of Economics, Autumn 1991, 22 (3), pp. 385-95.

Annals of Emergency Medicine, 1999

Angrist, J. "Lifetime Earnings and the Vietnam Era Draft Lottery: Evidence from Social Security Administrative Records." American Economic Review, June 1990, 80 (3), pp. 313-36.

Angrist, J. ; Krueger, A. "Does Compulsory School Attendance Affect Schooling and Earnings?" Quarterly Journal of Economics, November 1991, 106 (4), pp. 979-1014.

Arellano, M ; Bond.S. "Some Tests of Specification for Panel Data: Monte Carlo Evidence and an Application to Employment Equations". Review of Economic Studies. 1991. pp. 277-97.

Ayres, I. ; Levitt, S. "Measuring Positive Externalities from Unobservable Victim Precaution: An Empirical Analysis of Lojack." Quarterly Journal of Economics, February 1998, 113 (1), pp. 43-77.

Bar-Ilan, A. ; Sacerdote, B. "The Response to Fines and Probability of Detection in a Series of Experiments." National Bureau of Economic Research (Cambridge, MA). Working Paper No. 8638, December 2001.

Bayley, D. "Introduction to Chapter 2: Patrol," em Bayley.D e.d. "What Works in Policing", New York: Oxford University Press, 1998, pp. 26-30.

Beato, C. "Políticas Públicas de Segurança: Equidade, Eficiência e Accountability", Depto de Sociologia e Antropologia UFMG 
Beato, C. "Informação e Desempenho Policial", Centro de Estudos em Criminalidade e Segurança Pública UFMG.

Beato, C. ; Peixoto, B. ; Andrade, M. "Crime, Oportunidade e Vitimização", Centro de Estudos em Criminalidade e Segurança Pública UFMG.

Becker, G. "Crime and Punishment: An Economic Approach.” Journal of Political Economy, March-April 1968, 76 (2), pp. 169-217.

Cameron, S. “The Economics of Crime Deterrence: A Survey of Theory and Evidence.” Kyklos, May 1988, 41 (2), pp. 301-23.

Corman, H. ; Mocan, N. "A Time-Series Analysis of Crime, Deterrence, and Drug Abuse in New York City.” American Economic Review, June 2000, 90 (3), pp. 584-604.

Cornish, D. and Clarke, R. "Understanding Crime Displacement: An Application of Rational Choice Theory." Criminology, November 1987, 25 (4), pp. 933-47.23

Cotrim, B ; Duarte, P. “Álcool e Violência: Estudo dos Processo de Homicídio Julgados nos Tribunais de Juri de Curitiba", 2000.

Di Tella ; Schargrodsky “Do Police Reduce Crime? Estimates Using Allocation of Police Forces After Terrorist Attack". The American Economic Review, (2004).

Duggan, M. “More Guns, More Crime.” Journal of Political Economy, October 2001, 109 (5), pp. 1086-1114.

Eck, J. ; Maguire, E. "Have Changes in Policing Reduced Violent Crime? An Assessment of the Evidence," em A. Blumstein e J. Wallman "The Crime Drop in America". New York: Cambridge University Press, 2000, pp. 207-65. 
Ehrlich, I. "Participation in Illegitimate Activities: A Theoretical and Empirical Investigation.” Journal of Political Economy, May-June 1973, 81 (3), pp. 521-65.

Ehrlich, I ; Brower, G. "On the Issue of Causality in the Economic Model of Crime and Law Enforcement: Some Theoretical Considerations and Experimental Evidence." American Economic Review, May 1987, 77 (2), pp. 99-106.

Fajnzylber, P. ; Lederman, D. ; Loayza, N. "Crime and Victimization: An Economic Perspective." Economia, Fall 2000, 1 (1), pp. 219-302.

Freeman, R.. "Why Do So Many Young American Men Commit Crimes and What Might We Do About It?” Journal of Economic Perspectives, 1996, 10 (1), pp. 25-42.

Gomes, F. ; Paz, L. “The Determinants of Criminal Victimization in São Paulo State-Brazil”. Anpec. 2004

Greene, W. - Econometric Analysis

Gutierrez, M. ; Mendonça, M. ; Saschida, A. ; Loureiro, P. "Inequality and Criminality Revisited: Further Evidence from Brazil”. Anpec. 2004

Hart, O. "Corporate Governance: Some Theory and Implications", Economic Journal, May, 1995, 105(1), pp. 678-689

Hausman, J. "Specification Tests in Econometrics". Econometrica . 1978. 46(6) . pp. 12511271.

Hesseling, R. "Displacement: A Review of the Empirical Literature," em Clarke, R. "Crime Prevention Studies”, III. Monsey, NY: Criminal Justice Press, 1994, pp. 197-230. 
Kahn, T ; Zanetic, A. “O papel dos Municípios na Segurança Pública”. Estudos Criminológicos. 2005.

Kessler, D. ; Levitt, S. "Using Sentence Enhancements to Distinguish between Deterrence and Incapacitation.” Journal of Law and Economics, April 1999, 42 (1), pp. 343-63.

Kume, L. "Uma Estimativa dos Determinantes da Taxa de Criminalidade Brasileira: Uma Aplicação em Painel Dinâmico”. Anpec, 2004.

Levitt, S. "Using Electoral Cycles in Police Hiring to Estimate the Effect of Police on Crime." American Economic Review, June 1997, 87 (3), pp. 270-90.

Levitt, S. "Why Do Increased Arrest Rates Appear to Reduce Crime: Deterrence, Incapacitation or Measurement Error?” Economic Inquiry, July 1998, 36 (3), pp. 353-72.24

Levitt, S. "Using Electoral Cycles in Police Hiring to Estimate the Effect of Police on Crime: Reply." American Economic Review, September 2002, 92 (4), pp. 1244-50.

Levitt, S. "The Effect of Prison Population Size on Crime Rates: Evidence From Prison Overcrowding Litigation". NBER Working Paper Series, (May 1995), Vol. w5119.

Levitt, S. "Does Abortion Prevents Crime?" State Magazine. (Aug 1999). Vol. w5119.

Lochner, L ; Moretti, E. "The Effect of Education on Crime: Evidence From Prison Inmates, Arrests, and Self-Reports" The American Economic Review, (2004)

Lott, J. "More Guns, Less Crime”. The University of Chicago Press, 1998. 
Marvell, T. ; Moody, C. "Specification Problems, Police Levels, and Crime Rates." Criminology, November 1996, 34 (4), pp. 609-46.

Ministerio de Justice de lá República Argentina. "Estúdio de Victimización en Centros Urbanos de la Argentina.” Mimeo, 2000.

Mookherjee, D. ; Png, I. "Monitoring vis a vis Investigation in the Enforcement of Law." American Economic Review, June 1992, 82 (3), pp. 556-65.

Secretaria de Segurança Pública do Estado de São Paulo, Estudos Criminológicos - volume 1 a 4 $-(1998-2004)$.

Sherman, L. ; Gartin, P. ; Buerger, M. "Hot Spots of Predatory Crime: Routine Activities and the Criminology of Place.” Criminology, 1989, 27 (1), pp. 27-55.

Sherman, L. ; Weisburd, D. “General Deterrent Effects of Police Patrol in Crime "Hot Spots": A Randomized, Controlled Trial." Justice Quarterly, December 1995, 12 (4), pp. 625-648.

Silva, N. ; Kassouf, A. "Mercados de Trabalho Formal e Informal: Uma Análise da Discriminação e da Segmentação”. Nova Economia, 2000, pp. 41-77

STATA. Stata Reference Manual. Number 7, Vol. 3 Q-St, College Station Texas: Stata Press ,2001.

Williamson, O. ; Winter, S. "The Nature of the Firm: Origins, Evolution, and Development", Oxford University Press US, 1993.

Wooldridge, J. "Introductory Econometrics, A Modern Approach.” 